\title{
Glutamate-Mediated Blood-Brain Barrier Opening: Implications for Neuroprotection and Drug Delivery
}

\author{
Udi Vazana, ${ }^{1,2,3 \star}$ Ronel Veksler, ${ }^{1,2 \star}$ Gaby S. Pell, ${ }^{4,5 \star}$ Ofer Prager, ${ }^{1,2}$ Michael Fassler, ${ }^{1,2,3}$ Yoash Chassidim, ${ }^{1,2}$ \\ Yiftach Roth, ${ }^{5}$ Hamutal Shahar, ${ }^{4,5}$ Abraham Zangen, ${ }^{4}$ Ruggero Raccah, ${ }^{6}$ Emanuela Onesti, ${ }^{7}{ }^{\circ}$ Marco Ceccanti, ${ }^{7}$ \\ [Claudio Colonnese, ${ }^{8}$ Antonio Santoro, ${ }^{8}$ Maurizio Salvati, ${ }^{8}$ Alessandro D'Elia, ${ }^{8}$ CValter Nucciarelli, ${ }^{8}$ \\ CMaurizio Inghilleri, ${ }^{7}$ and Alon Friedman ${ }^{1,2,9}$ \\ Departments of ${ }^{1}$ Cognitive and Brain Sciences, ${ }^{2}$ Physiology and Cell Biology, ${ }^{3}$ Biomedical Engineering, and ${ }^{4}$ Life Sciences, Zlotowski Center for \\ Neuroscience, Ben-Gurion University of the Negev, Beer-Sheva, 84105 Israel, ${ }^{5}$ Brainsway, Jerusalem, 9777518 Israel, ${ }^{6}$ Atid, Rome 00187, Italy, Departments \\ of ${ }^{7}$ Neurology and Psychiatry and ${ }^{8}$ Neurological Sciences, Sapienza University of Rome, Rome 00185, Italy, and ${ }^{9}$ Department of Medical Neuroscience, \\ Faculty of Medicine, Dalhousie University, Halifax, Nova Scotia B3H 4R2, Canada
}

The blood- brain barrier is a highly selective anatomical and functional interface allowing a unique environment for neuro-glia networks. Blood-brain barrier dysfunction is common in most brain disorders and is associated with disease course and delayed complications. However, the mechanisms underlying blood-brain barrier opening are poorly understood. Here we demonstrate the role of the neurotransmitter glutamate in modulating early barrier permeability in vivo. Using intravital microscopy, we show that recurrent seizures and the associated excessive glutamate release lead to increased vascular permeability in the rat cerebral cortex, through activation of NMDA receptors. NMDA receptor antagonists reduce barrier permeability in the peri-ischemic brain, whereas neuronal activation using high-intensity magnetic stimulation increases barrier permeability and facilitates drug delivery. Finally, we conducted a double-blind clinical trial in patients with malignant glial tumors, using contrast-enhanced magnetic resonance imaging to quantitatively assess blood- brain barrier permeability. We demonstrate the safety of stimulation that efficiently increased blood-brain barrier permeability in 10 of 15 patients with malignant glial tumors. We suggest a novel mechanism for the bidirectional modulation of brain vascular permeability toward increased drug delivery and prevention of delayed complications in brain disorders.

Key words: blood-brain barrier; glutamate; imaging; $N$-methyl-D-aspartate; transcranial magnetic stimulation

Significance Statement

In this study, we reveal a new mechanism that governs blood- brain barrier (BBB) function in the rat cerebral cortex, and, by using the discovered mechanism, we demonstrate bidirectional control over brain endothelial permeability. Obviously, the clinical potential of manipulating BBB permeability for neuroprotection and drug delivery is immense, as we show in preclinical and proof-of-concept clinical studies. This study addresses an unmet need to induce transient BBB opening for drug delivery in patients with malignant brain tumors and effectively facilitate BBB closure in neurological disorders.

\section{Introduction}

The blood-brain barrier (BBB) is a highly specialized interface that separates the circulating blood from the extracellular fluid in

Received Feb. 18, 2016; revised May 31, 2016; accepted June 6, 2016.

Author contributions: U.V., R.V., G.S.P., A.Z., M.I., and A.F. designed research; U.V., R.V., G.S.P., O.P., M.F., Y.C., Y.R., H.S., R.R., E.O., M.C., C.C., A.S., M.S., A.D., V.N., and A.F. performed research; U.V., R.V., O.P., M.F., Y.C., Y.R., H.S., A.Z., R.R., E.O., M.C., C.C., A.S., M.S., A.D., and V.N. contributed unpublished reagents/analytic tools; U.V., R.V., G.S.P., and A.F. analyzed data; U.V., R.V., G.S.P., M.I., and A.F. wrote the paper.

*U.V., R.V., and G.S.P. contributed equally to this work.

This study was supported by the European Union's Seventh Framework Program (FP7/2007-2013; Grant Agreement 602102, EPITARGET), the NIH-National Institute of Neurological Disorders and Stroke (R01/NINDS NS066005), the Israel Science Foundation, the Nova Scotia Health Research Foundation and partly by Brainsway.

Y.R. and A.Z. are key inventors on patent applications on multichannel TMS stimulator technology, have financial interests in Brainsway, and receive financial support from this company. G.S.P. and H.S. are employees of Brainsway. the brain in the CNS. The BBB is formed at the level of endothelial cells, which are connected by tight-junction protein complexes that seal together the paracellular space. It consists of specialized transcellular transport systems, a basal membrane, and astrocytic end feet (Abbott et al., 2006). The selective nature of the BBB allows the formation of a unique extracellular milieu within brain neuropil (Abbott et al., 2006), essential for normal brain function. In most common brain disorders, including epilepsy, traumatic brain injury, stroke, and neurodegenerative diseases, the

Correspondence should be addressed to Alon Friedman, 5850 College Street, P.0. Box 15000, Halifax, Nova Scotia B3H 4R2, Canada. E-mail: alon.friedman@dal.ca.

D0I:10.1523/JNEUROSCI.0587-16.2016

Copyright $\odot 2016$ the authors $\quad 0270-6474 / 16 / 367727-13 \$ 15.00 / 0$ 
A

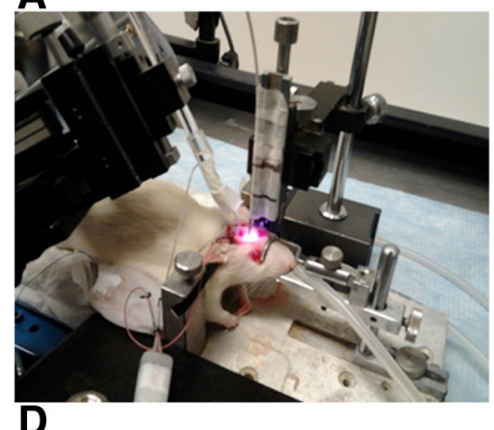

D

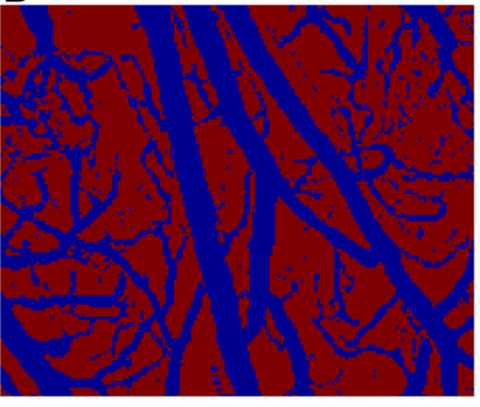

B

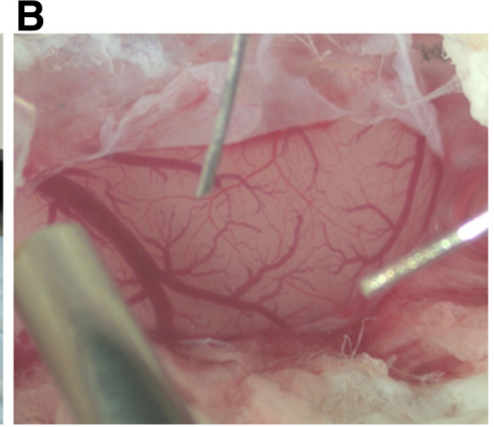

E

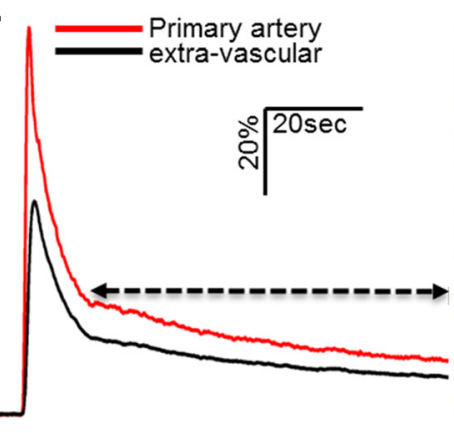

C

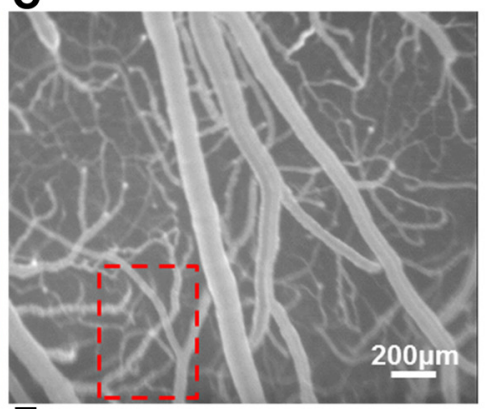

$\mathbf{F}$

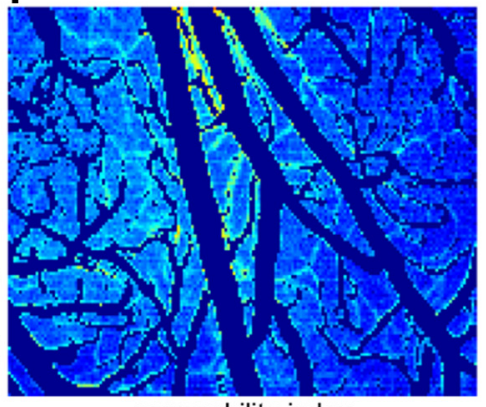

permeability index

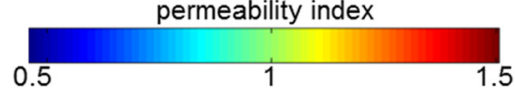

Figure 1. Direct cortical imaging in anesthetized rodents is analyzed for quantitative assessment of BBB permeability. $A$, A rat is anesthetized and placed in a stereotactic frame (see Materials and Methods). $\boldsymbol{B}$, Craniotomy is used to expose the neocortex (see Materials and Methods). $\boldsymbol{C}$, Cortical surface following injection of NaFlu. $\boldsymbol{D}$, Rescaling and segmentation of the fluorescence image. The product is a binary image in which vascular and extravascular areas are contrasted. $\boldsymbol{E}$, Averaging pixel intensities through time in the primary artery (marked by red frame in $\boldsymbol{C}$ ) forms the AlF (primary artery, red). Each extravascular pixel is also represented by an IT curve (extravascular, black). Tracer residues in extravascular space are assessed by comparing both functions in the marked time span (arrow). The result is a per-pixel numerical parameter reflective of $\mathrm{BBB}$ permeability level (PI). $\boldsymbol{F}$, Spatial mapping of BBB permeability.

BBB may be compromised (Benveniste et al., 1984; Nishizawa, 2001; Brown and Davis, 2002; Davies, 2002; Seiffert et al., 2004; van Vliet et al., 2007; Friedman, 2011) and could contribute to neural dysfunction, neural network reorganization, and degeneration, thus modifying disease progression (Benveniste et al., 1984; Seiffert et al., 2004; van Vliet et al., 2007; Tomkins et al., 2008). However, the mechanisms underlying BBB dysfunction in brain disorders are not fully understood.

The potential of excessive neuronal activation to increase brain vascular permeability to blood constituents is supported by the following indirect evidence: (1) seizures, and in particular when recurrent or prolonged, such as in status epilepticus (SE), are associated with BBB dysfunction (Nitsch and Hubauer, 1986; Friedman, 2011); (2) increased BBB permeability is often a hallmark of the perilesional brain in ischemia, trauma, and tumors, neurological conditions associated with neuronal hyperexcitability, epileptic seizures, and spreading depolarizations (Davies, 2002; Tomkins et al., 2008; Schoknecht et al., 2014); (3) the major excitatory neurotransmitter, glutamate, has been demonstrated to increase permeability in cultured brain endothelial cells (Sharp et al., 2003; András et al., 2007); and (4) whole-brain stimulation, such as that performed during electroconvulsive treatment for severe depression, has been shown to accompany increased glutamate levels (Zangen and Hyodo, 2002) and BBB breakdown (Mottaghy et al., 2003). Therefore, we tested the hypothesis that hypersynchronized neuronal activation and excessive accumulation of extracellular glutamate (Bradford, 1995) result in $\mathrm{BBB}$ dysfunction.

\section{Materials and Methods}

Animal handling. All experimental procedures in animals were approved by the Ben-Gurion University ethics committee for animal testing. Un- less otherwise mentioned, all materials were purchased from SigmaAldrich. Surgical procedures in male Sprague Dawley rats (200-380 g body weight) were performed as reported previously (Prager et al., 2010). Rats were deeply anesthetized by intraperitoneal administration of ketamine $(100 \mathrm{mg} / \mathrm{ml}, 0.08 \mathrm{ml} / 100 \mathrm{~g})$ and xylazine $(20 \mathrm{mg} / \mathrm{ml}, 0.06 \mathrm{ml} / 100$ g) or oxygen-enriched isoflurane (1-1.5\%) inhalation for $\sim 3 \mathrm{~h}$ as detailed in Results. The tail vein was catheterized, and animals were placed in a stereotactic frame (Fig. 1A) under a SteREO Lumar V12 fluorescence microscope (Zeiss). Body temperature was continuously monitored and kept stable at $37 \pm 0.5^{\circ} \mathrm{C}$ using a feedback-controlled heating pad (Physitemp). Heart rate, breath rate, and oxygen saturation levels were continuously monitored using MouseOx (STARR Life Sciences). A cranial section ( $4 \mathrm{~mm}$ caudal, $2 \mathrm{~mm}$ frontal, $5 \mathrm{~mm}$ lateral to bregma) was removed over the right sensorimotor cortex. The dura and arachnoid layers were removed (Fig. 1B), and the exposed cortex was continuously perfused with artificial CSF (ACSF; Prager et al., 2010) containing the following (in mM): $124 \mathrm{NaCl}, 26 \mathrm{NaHCO}_{3}, 1.25 \mathrm{NaH}_{2} \mathrm{PO}_{4}, 2 \mathrm{MgSO}_{4}, 2$ $\mathrm{CaCl}_{2}, 3 \mathrm{KCl}$, and 10 glucose, $\mathrm{pH}$ 7.4. To block neuronal activity, tetrodotoxin (TTX; $10 \mu \mathrm{M}$; Narahashi et al., 1964), 6-cyano-2,3-dihydroxy-7-nitro-quinoxaline (CNQX; $50 \mu \mathrm{M}$; Yoshiyama et al., 1995), D-(-)-2-amino-5-phosphonopentanoic acid (D-AP-5; $50 \mu \mathrm{M}$; Morris, 1989), and picrotoxin (PTX; $50 \mu \mathrm{M}$; Yoon et al., 1993) were added to the ACSF. To induce prolonged seizures (SE), 4-aminopyridine (4-AP; 500 $\mu \mathrm{M}$; Uva et al., 2013) or PTX (100 $\mu \mathrm{M})$ were added to the ACSF. Electrocorticogram (ECoG) was recorded using bipolar electrodes and a telemetric recording system (Data System International). In some cases, thrombotic stroke was induced using photothrombosis (Watson et al., 1987). Detection of calcium ions in the rat cortex was done with calcium chelators as reported previously (Stosiek et al., 2003): $50 \mu \mathrm{g}$ of the fluorescent chelator Oregon green-BAPTA-1AM (OGB; Life Technologies) were dissolved in $4 \mu \mathrm{l}$ of dimethylsulfoxide (DMSO) containing $20 \%$ pluronic F-127. This mixture was diluted in $36 \mu$ lof a loading solution containing the following (in $\mathrm{mM}$ ): $150 \mathrm{NaCl}, 2.5 \mathrm{KCl}$, and 10 HEPES in $\mathrm{ddH}_{2} \mathrm{O}, \mathrm{pH}$ 7.4. The exposed cortex was incubated with the final mixture 
Table 1. Clinical characteristics of patients

\begin{tabular}{|c|c|c|c|c|c|c|c|c|}
\hline Subject ID & Gender & Age (years) & Date of operation & Tumor site & Side & Anti-epileptic drugs at present & KPS & Phase of disease \\
\hline 1 & M & 70 & $03 / 07 / 2010$ & FPO & $\mathrm{L}$ & No & 70 & Progression \\
\hline 2 & M & 76 & $14 / 09 / 2006$ & 0 & $\mathrm{~L}$ & Yes & 90 & Stable \\
\hline 3 & M & 53 & $08 / 03 / 2010$ & $P$ & $\mathrm{~L}$ & Yes & 100 & Stable \\
\hline 4 & M & 47 & $17 / 05 / 2010$ & $\mathrm{P}$ & $\mathrm{R}$ & Yes & 100 & Stable \\
\hline 5 & $\mathrm{~F}$ & 41 & $24 / 09 / 2008$ & $\mathrm{~F}$ & $\mathrm{~L}$ & No & 100 & Stable \\
\hline 6 & M & 48 & $23 / 10 / 2007$ & $P$ & $\mathrm{R}$ & Yes & 100 & Stable \\
\hline 7 & M & 62 & $04 / 04 / 2007$ & 0 & $\mathrm{~L}$ & Yes & 100 & Stable \\
\hline 8 & $\mathrm{~F}$ & 63 & $28 / 11 / 2009$ & T0 & $\mathrm{R}$ & Yes & 100 & Stable \\
\hline 9 & M & 36 & $04 / 08 / 2010$ & FTP & $\mathrm{L}$ & Yes & 100 & Stable \\
\hline 10 & $\mathrm{~F}$ & 32 & $21 / 10 / 2010$ & $\mathrm{FT}$ & $\mathrm{L}$ & Yes & 100 & Stable \\
\hline 11 & M & 54 & $09 / 12 / 2010$ & $\mathrm{~T}$ & $\mathrm{~L}$ & Yes & 100 & Stable \\
\hline 12 & M & 71 & $27 / 11 / 2008$ & TP & $\mathrm{R}$ & Yes & 90 & Stable \\
\hline 13 & $\mathrm{~F}$ & 59 & $21 / 07 / 2010$ & $\mathrm{~F}$ & $\mathrm{R}$ & Yes & 100 & Stable \\
\hline 14 & $\mathrm{~F}$ & 73 & $12 / 10 / 2010$ & $\mathrm{~T}$ & $\mathrm{~L}$ & Yes & 100 & Stable \\
\hline 15 & $M$ & 56 & $06 / 11 / 2009$ & $\mathrm{~T}$ & $\mathrm{~L}$ & No & 90 & Stable \\
\hline
\end{tabular}

Age of subjects at time of study is listed. Tumor site: $F$, frontal; 0 , occipital; P, parietal; $T$, temporal; $R$, right; L, left; KPS, Karnofsky performance status.

for $1 \mathrm{~h}$. Detection of nitric oxide (NO) ions was done with the NO sensor 4-amino-5-methylamino-2' ${ }^{\prime} 7^{\prime}$-difluorofluorescein diacetate (DAF-FM; Life Technologies; Schoknecht et al., 2014). A stock solution (1 mM in DMSO) was diluted to $200 \mu \mathrm{M}$ in ACSF and mounted on the exposed cortex for $30 \mathrm{~min}$. Probe-based confocal laser microscopy (PCLM) was performed using Cellvizio dual band (Mauna Kea Technologies) at 488 and $660 \mathrm{~nm}$ and analyzed with in-house developed MATLAB scripts. For drug delivery experiments, penicillin $\mathrm{G}$ sodium was administered intravenously $(0.833 \mathrm{MU} / \mathrm{kg}$ in $0.9 \% \mathrm{NaCl})$. In some cases, oxygen levels were measured in brain parenchyma using a miniaturized Clark-type oxygen glass-microsensor (UNISENSE), positioned within the parenchyma, adjacent to the selected arteriole for continuous monitoring.

Fluorescent angiography and BBB permeability assessment. Dynamic imaging of regional cerebral blood flow and BBB permeability measurements were performed as reported previously (Prager et al., 2010; Schoknecht et al., 2014; Chassidim et al., 2015) with minor adds-on to the image analysis methods. The non-BBB permeable fluorescent dye sodium fluorescein $(\mathrm{NaFlu})$ was injected intravenously $(1 \mathrm{mg} / \mathrm{ml}, 0.2$ $\mathrm{ml} /$ injection, in $0.9 \% \mathrm{NaCl})$. Full-resolution $(658 \times 496 \mathrm{pixel})$ images of cortical surface vessels were obtained ( 5 frames/s, EMCCD camera, DL658 M-TIL; Andor Technology; Fig. 1C) before, during, and after injection of the tracer. Offline image analysis was performed using MATLAB (MathWorks) and included subpixel image registration, segmentation using noise filtration, hole-filling and adaptive threshold to produce a binary image, and separating blood vessels from extravascular regions (Fig. 1D). Signal intensity changes over time and space were then analyzed so that each pixel was represented by intensity versus time (IT) curve (Fig. 1E). An arterial IT curve [arterial input function (AIF)] was created by spatially averaging signal intensity through time in the primary artery. A BBB permeability index (PI) was calculated for each extravascular pixel as the ratio between IT curve and AIF, from the point of the second decline phase to the end of the measurement $(\sim 250-300 \mathrm{~s}$, Fig. 1E): PI $=\frac{1}{T} \int_{t_{\mathrm{cr}}}^{t_{\mathrm{end}}} \frac{I_{\mathrm{EV}}}{I_{\mathrm{AIF}}}(t) d t$, where $T=t_{\text {end }}-t_{\mathrm{cr}}$. The PI indicates how much tracer remains in extravascular tissue in relation to the applied amount. PI $>1$ indicates tracer accumulation and defines BBB dysfunction. Fitting a PI to each extravascular pixel enabled spatial mapping of BBB permeability (Fig. $1 F$ ). The PI for each vascular pixel was set to 0 , and therefore vessels were excluded from the map. The global permeability of a region was calculated by averaging its PI values. Permeability measurements with this approach are possible only for regions with fully functional vasculature as the transfer of molecules between vessel and parenchyma is quantified. Increased permeability in damaged vessels is not depicted here. The method was validated in well established models of BBB dysfunction such as cortical perfusion of sodium deoxycholate and photo-induced stroke (Prager et al., 2010; Schoknecht et al., 2014; Chassidim et al., 2015). Additionally, qualitative assessment of BBB permeability was done by intravenously injecting the albumin-binding dye
Evans blue (EB; $1 \mathrm{mg} / \mathrm{ml}, 2.4 \mathrm{ml} / \mathrm{kg}$, in $0.9 \% \mathrm{NaCl}$; Wolman et al., 1981), extraction of brains after cardiac perfusion (4\% paraformaldehyde in PBS), and verifying extravasation of the dye. Assessments of vascular diameter in the exposed cortical section were performed by transforming vascular pixel quantification into metric measurements.

Transcranial magnetic stimulation. Repetitive transcranial magnetic stimulation (rTMS) was applied to the exposed cortex of the rat using a Rapid $^{2}$ stimulator (Magstim) and a conventional circular coil $(58 \mathrm{~mm}$ outer diameter, $56 \mathrm{~mm}$ inner diameter, $1.5 \mathrm{~mm}$ thickness, $18.4 \mu \mathrm{H}$ inductance; Brainsway; Gersner et al., 2011) at either 1 or $10 \mathrm{~Hz}$ and as real or sham. Two stimulation protocols were applied: (1) low frequency: 1 $\mathrm{Hz}, 50 \mu$ s pulse duration; duration, $50 \mathrm{~s}$ train; intertrain interval, $60 \mathrm{~s}$; number of trains, 5; total number of pulses, 250; and (2) high frequency: $10 \mathrm{~Hz}, 50 \mu$ s pulse duration; train duration, $1 \mathrm{~s}$; intertrain interval, $9 \mathrm{~s}$; number of trains, 5 ; trains were repeated 5 times with 60 s intervals; total number of pulses, 250. In both protocols, stimulation intensity was set to $130 \%$ of resting motor threshold (RMT; the minimal intensity required to initiate a motor response indicated by contralateral paw/whisker motion). Sham stimulation was applied by placing a coil in the same location, above the exposed cortex, while stimulating a second coil, placed at a distance of 100-120 cm away from the skull. Sham stimulation did not evoke any motor response. BBB permeability analysis was performed before and after stimulation.

Thrombotic stroke. The photo-reactive substance, rose bengal (RB; 7.5 $\mathrm{mg} / \mathrm{ml}$ in $0.9 \% \mathrm{NaCl}, 0.133 \mathrm{ml} / 100 \mathrm{~g}$ ), was injected into the tail vein while a vascular region in the exposed cortex was laser illuminated at $523 \mathrm{~nm}(5$ $\mathrm{mW}$; CNI Lasers). The transformation of RB into free radicals, binding to platelets, and the formation of clots occurred within $15 \mathrm{~min}$ (Prager et al., 2010; Schoknecht et al., 2014).

ECoG recording and analysis. ECoG was recorded using a telemetric system (Data System International). Two electrodes were implanted, one attached to an intracranial screw adjacent to the exposed cortex and the second placed over the exposed cortex while secured with bone wax (Ethicon) and dental cement (GC America). In-house MATLAB scripts were used to display and record signals for post-processing. Signals were sampled at $200 \mathrm{~Hz}$ and filtered using a MATLAB simulated Butterworth filter to display only the desired frequency band $(10-40 \mathrm{~Hz})$. The mean power was calculated using the MATLAB "pwelch" function.

Patient monitoring. The human trial was approved by the local ethics committee at La-Sapienza University, Rome, Italy. All patients gave written consent for participation in the trial. A total of 15 subjects (aged 32-76 years, 10 males) with histologically confirmed glioblastoma multiform (GBM, grade IV) were enrolled for a short pilot study. Patients with cardiac pacemakers, neurostimulators, pumps, or medical or surgical clips were excluded. All subjects underwent previous surgery (craniotomy with gross tumor resection) at least 6 months before the study. Patient characteristics are listed in Table 1. After resection, subjects underwent standard postoperative treatment with radiotherapy, followed 
by adjuvant chemotherapy using temozolomide. At the time of the study, subjects were in a stable condition and were not on steroid medication. Treatment protocols were not modified during the study. In addition, four non-tumor control subjects were recruited from alternative deep TMS (dTMS) trials (pain and aphasia) that were taking place at the same hospital (aged 26-56 years, three males). Subjects were analyzed for BBB permeability using dynamic contrast-enhanced magnetic resonance imaging (DCE-MRI; Chassidim et al., 2013; see Fig. 6).

Magnetic resonance imaging for BBB permeability assessment. Imaging was performed with a $1.5 \mathrm{~T}$ Intera scanner (Phillips Healthcare) containing a six-element receiver coil. A standard battery of anatomical scans was performed during the prestimulation session. These scans included diffusion-weighted imaging, fluid-attenuated inversion recovery, T2weighted scans, and a high-resolution T1-weighted anatomical scan (3D gradient echo; TR, $8.6 \mathrm{~ms}$; TE, $3.5 \mathrm{~ms}$; TI, $900 \mathrm{~ms}$; FOV, $240 \times 240 \mathrm{~mm}$; matrix, $256 \times 256$; slice thickness, $1.2 \mathrm{~mm}$; 150 slices; flip angle, $8^{\circ}$ ). In addition, two baseline scans were performed with DCE-MRI (spin echo; TR, $1000 \mathrm{~ms}$; TE, $8 \mathrm{~ms}$; FOV, $240 \times 180 \mathrm{~mm}$; matrix, $256 \times 192$; slice thickness, $3 \mathrm{~mm}$ with no gap; 42 slices; two concatenations; acquisition time, $3 \mathrm{~min}, 14 \mathrm{~s}$ ). The DCE-MRI acquisition consisted of at least seven longitudinal scans using the same protocol. Images were processed using Statistical Parametric Mapping (SPM; MATLAB; http://www.fil.ion.ucl. ac.uk/spm), FSL (for FMRIB Software Library; Functional MRI of the Brain), NIH ImageJ (National Institutes of Health), and in-house scripts created with MATLAB. Preprocessing was performed using SPM and included coregistration, segmentation, spatial normalization, and Gaussian smoothing with a $2 \times 2 \times 6(x, y, z) \mathrm{mm}$ kernel. Because of difficulties in performing stimulation within the scanner, contrast agent (gadopentetic acid, gadolinium-diethylenetriamine pentaacetic acid, 10 $\mathrm{ml}$, Magnevist; Bayer) was injected at the end of stimulation, and imaging started 3-5 min later. As a result, pharmacokinetic models that require AIF measurement, e.g., the widely used Tofts model (Tofts, 1997), could not be used. Therefore, a simplified form of DCE-MRI analysis was used as recently published (Chassidim et al., 2013, 2015; Veksler et al., 2014). To enable intrasubject and intersubject comparisons and compensate for potential differences in injection and blood flow, slope maps were normalized by dividing each voxel by the mean slope value in a region of interest drawn in the superior sagittal sinus: $s \hat{l}_{\mathrm{t}}=s \mathrm{~s}_{\mathrm{t}} / \mathrm{sl}_{\mathrm{sag}}$, where $\mathrm{sl}$ is slope, $\mathrm{t}$ is tissue, and sag is superior sagittal sinus, respectively (Chassidim et al., 2013). Subsequent analysis was restricted to voxels assigned as gray or white matter components from segmentation of the high-resolution anatomical scan. The upper limit of normal vascular permeability was calculated using the cumulative distribution function (CDF) of the tissue-masked slope maps. These were derived from the slope values of the hemisphere contralateral to the resected tumor and both hemispheres for the control group, in both cases after "sham" stimulation. The 95th percentile of the combined CDF was defined as the threshold. The following masks of anatomical areas of interest were created and used to measure permeability values: tumor bed, peritumoral area, contralateral hemisphere, and ipsilateral hemisphere relative to the tumor (the latter region excluding the tumor bed; see Fig. $7 C$ ). Note that the term "tumor bed" is used interchangeably with the region corresponding to the resected tumor zone. The mask of the tumor bed was created by tracing the resected tumor outline on each slice of both the high-resolution anatomical scan and the first DCE-MRI scan after sham stimulation. The conjunction of these two masks was then defined as the tumor bed. The peritumoral region was created by subtraction of the tumor bed mask from a dilated tumor bed mask (created in FSL by mean dilation of nonzero voxels). For each mask of every scan, two parameters were calculated: (1) the mean value of the slope map; and (2) the percentage of voxels with abnormally high slope values [suprathreshold (ST)]. Examination of the effect on BBB permeability was performed using these two parameters. Slope differences were calculated as $100 \times\left(\mathrm{sl}_{1}-\mathrm{sl}_{2}\right) /\left|\mathrm{sl}_{2}\right|$.

dTMS. dTMS was delivered to human subjects at $1 \mathrm{~Hz}$, on the anterior periphery of the resected tumor bed using the newly designed $\mathrm{H}$-coil (Brainsway; Zangen et al., 2005; Roth et al., 2007) placed inside a specialized helmet. Human subjects presented on 2 consecutive days to receive dTMS, followed by DCE-MRI. The stimulation location on the scalp was selected on the first day after examination of the subject's previous neu- roimaging and in consultation with the treating oncologist, with the aim of consistently selecting an area on the anterior periphery of the resected tumor bed. The integrated coil design included an additional, independent "sham" coil that produces no significant level of cortical stimulation but reproduces a similar degree of auditory and scalp sensations as the "real" dTMS coil. Choice of real/sham was done via switch in the stimulation apparatus. Stimulation was performed each day using either real or sham coils, with the patients and operators blinded to the choice. The order of stimulation was counterbalanced across subjects. The focal point of the coil was marked on the scalp with MRI-visible fiducials. A radio frequency identification card-based system controlled blinded switching between the coils. Comparison of BBB permeability was done between post-real and post-sham states. For each patient, RMT was determined before each treatment with the coil placed on the hand area of the motor cortex ipsilateral to the stimulation site (Roth et al., 2007). The RMT was defined as the lowest TMS intensity capable of evoking a motor reaction in the thumb as determined by a combination of visual inspection and electromyogram recording of the abductor pollicis brevis muscle. Stimulation parameters were defined based on the animal study results and safety protocols (Rossi et al., 2009) and were as follows: frequency, $1 \mathrm{~Hz}$; pulse duration, $360 \mu \mathrm{s}$; train duration, $50 \mathrm{~s}$; intertrain interval, $60 \mathrm{~s}$; number of trains, 5; total number of pulses, 250; stimulation intensity, $130 \%$ of RMT. The consistent positioning of the stimulation coil on the intended target location was facilitated by the use of a simple device developed in-house, based on the touching together of two small metal contacts placed on the coil focus and the stimulation location, respectively. A flash of an LED and an audible buzz indicated the correct positioning.

Experimental design. No blinding was performed in animal studies. Naive animals were randomly selected for treatment. Data were analyzed identically (regardless of treatment selection) using MATLAB algorithms developed in-house and validated in advance. Human patients and operators were blinded to the choice of sham versus real dTMS.

Statistical analysis. Unless otherwise mentioned, mean \pm SEM are given. All comparisons were made using two-tailed Mann-Whitney $U$ or Wilcoxon's rank-sum tests (Mann-Whitney or Wilcoxon in text). $p=$ 0.05 was defined as the level of significance. Statistical analysis was performed using SPSS (IBM).

\section{Results}

\section{Seizures result in BBB opening}

We first tested whether focally induced cortical seizures are associated with increased vascular permeability. Under deep anesthesia (ketamine and xylazine; see Materials and Methods), we used intravital microscopy and the open-window method (Fig. 1) for simultaneous vascular imaging and ECoG recording. Recurrent seizures were induced using local application of the potassium channel blocker 4-AP, or blocker of the $\mathrm{GABA}_{\mathrm{A}}$ receptor, PTX ( $n=6$ and $n=2$, respectively). We quantitatively assessed BBB integrity by analyzing angiographic fluorescence imaging data (Prager et al., 2010; Fig. 1). Seizures were accompanied by a significant immediate increase in vessel diameter $(10.05 \pm 1.01 \%$, $n=8, p=0.01$, Wilcoxon; Fig. $2 A, B)$. Vessel permeability to $\mathrm{NaFlu}$ increased as soon as $\sim 10 \mathrm{~min}$ from seizure onset $(20.01 \pm$ 7.24\%, $n=8, p=0.01$, Wilcoxon; Fig. $2 C, E, F)$ and remained elevated during recurrent seizures $(30 \mathrm{~min}$ from seizure onset permeability increased by $14.17 \pm 4.65 \%, n=7, p=0.02$, Wilcoxon; Fig. $2 F$ ). To rule out ischemia as an underlying cause for increased endothelial permeability, we measured tissue oxygen levels during seizures using oxygen glass microelectrodes $(n=4)$. At the beginning of seizures, tissue oxygen level was transiently reduced by $27.76 \%$ from $76.74 \pm 28.14$ to $55.44 \pm 22.43 \mathrm{mmHg}$ ( $p=0.07$, Wilcoxon) and, because of vasodilation (Fig. $2 B$ ), was quickly (within $158.5 \pm 24.83 \mathrm{~s}$ ) increased to $134.66 \pm 44.14$ $\mathrm{mmHg}$, gradually returning to baseline $(81.48 \pm 32.7 \mathrm{mmHg})$ after seizure termination. Thus, a relatively mild and brief reduc- 
A ACSF

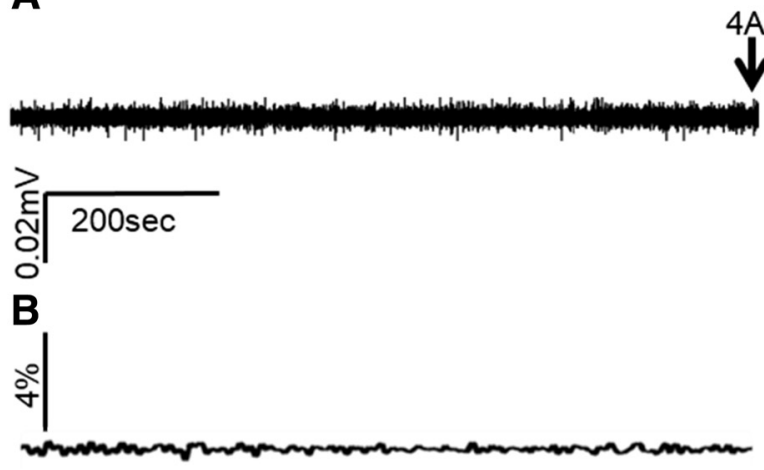

C

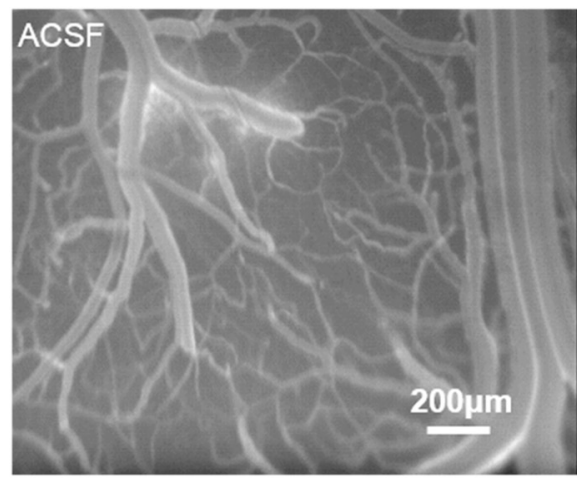

$\mathbf{E}$

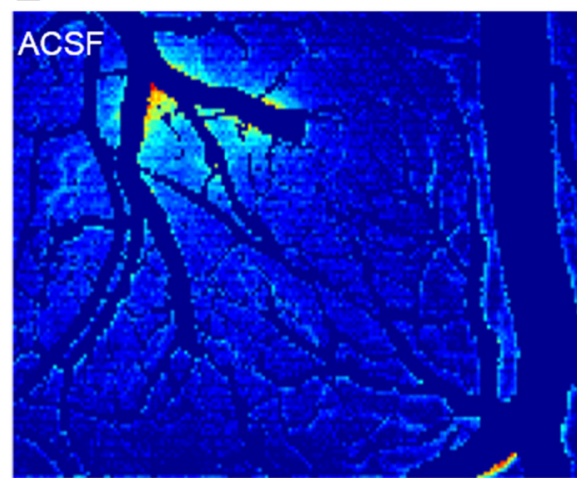

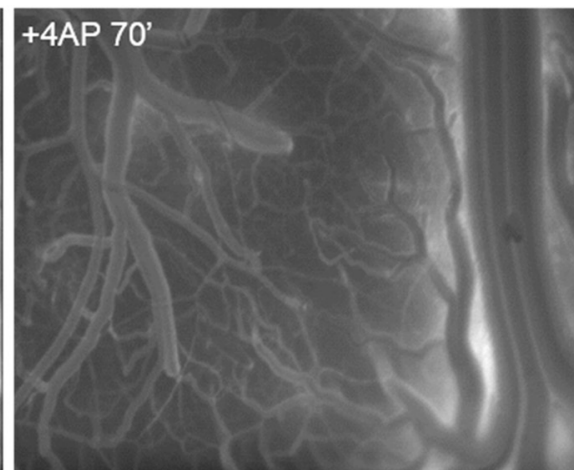

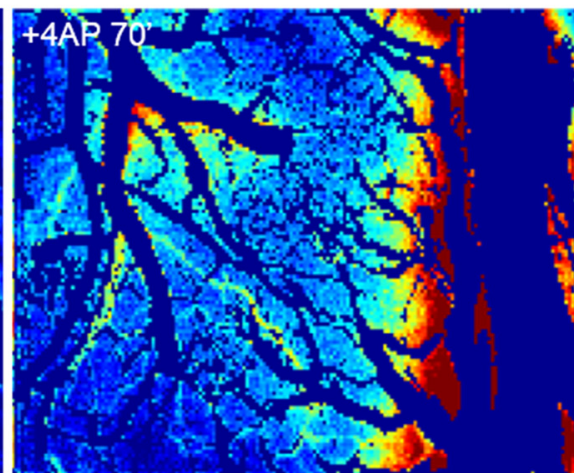

permeability index

$+4 \mathrm{AP}$

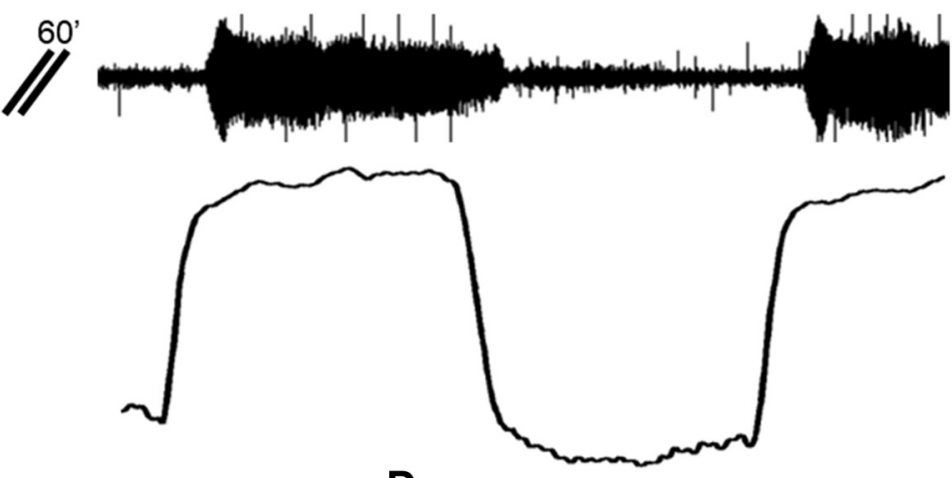

D
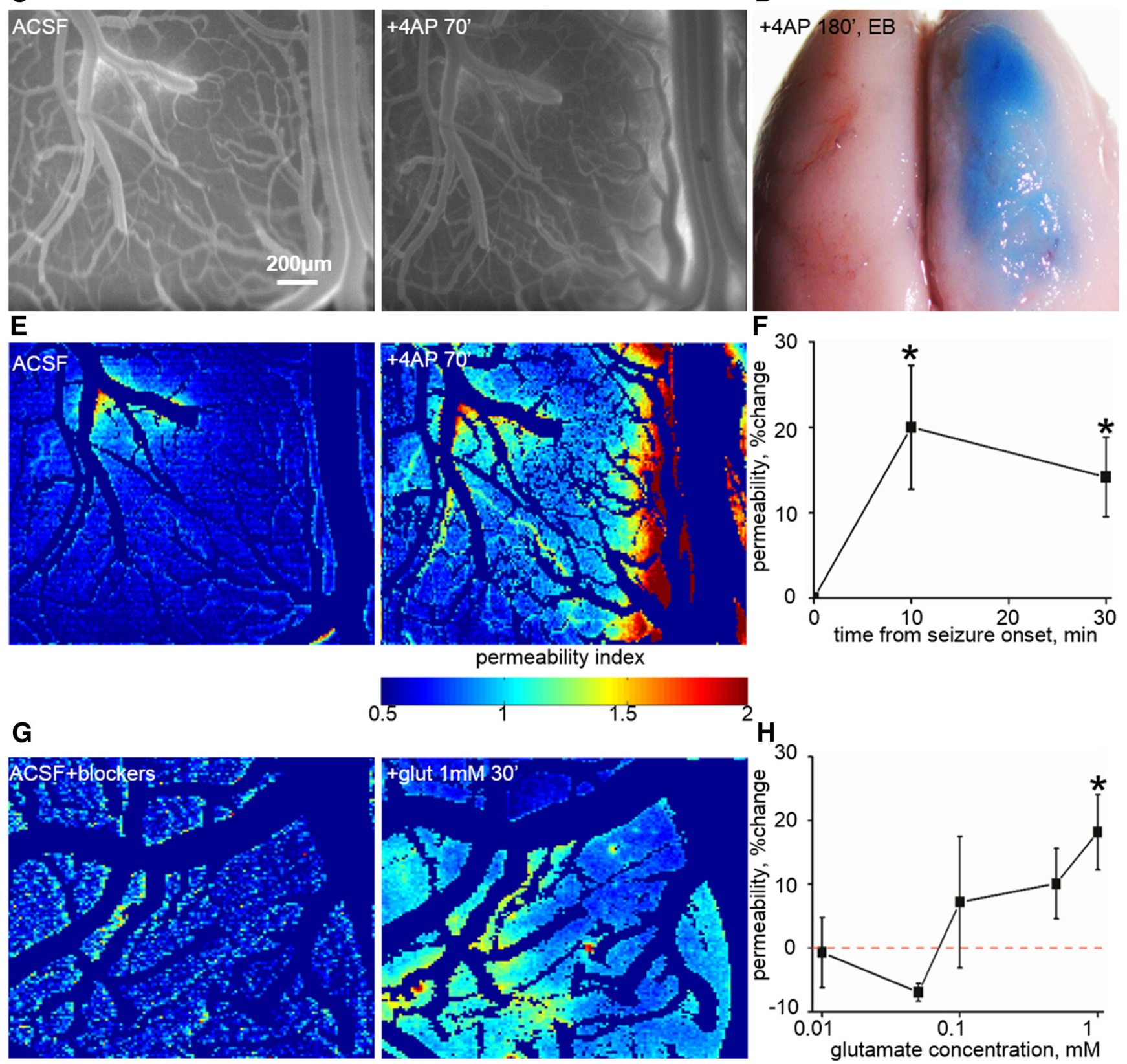

Figure 2. BBB dysfunction after focal cortical seizures and excess glutamate. $A, E C 0 G$ recordings from an anesthetized rat before (ACSF) and after topical 4-AP application ( $+4 A P)$. After 60 min under 4-AP exposure, recurrent seizures were recorded. $\boldsymbol{B}$, Seizure activity was accompanied by an increase in vessel diameter $(10.05 \pm 1.01 \%, n=8, p=0.01)$. C, Fluorescence imaging before (ACSF) and 70 min after 4-AP $\left(+4 A P 70^{\prime}\right.$ ) showing extravascular dye, indicative of BBB dysfunction. $\boldsymbol{D}$, The effect of recurrent seizures on the permeability of vessels is noticed by EB (see Materials and Methods) extravasation in the treated hemisphere alone. $E$, BBB permeability maps (color codes for the extent of permeability) depicting the effect (Figure legend continues.) 
A

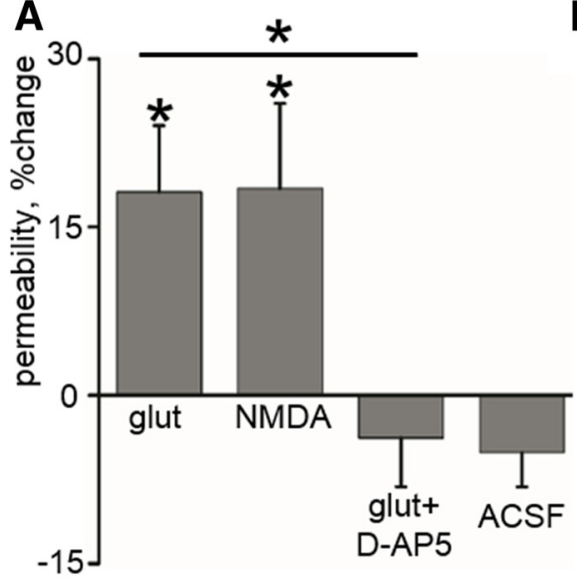

B

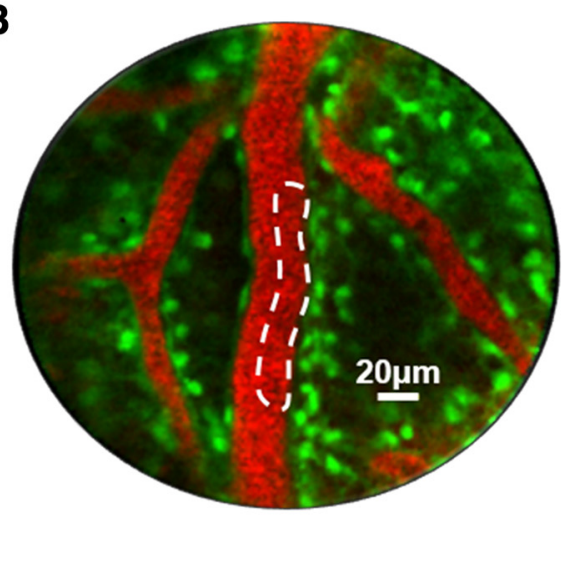

C

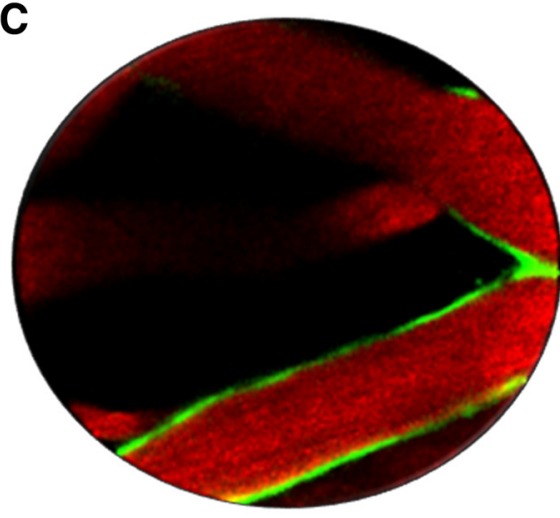

D

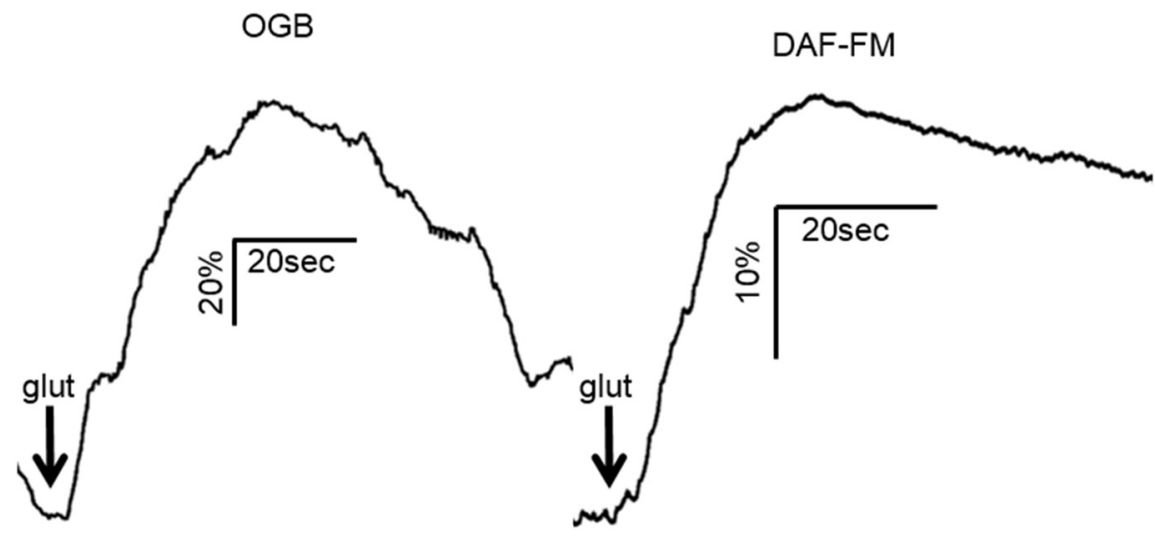

$\mathbf{F}$

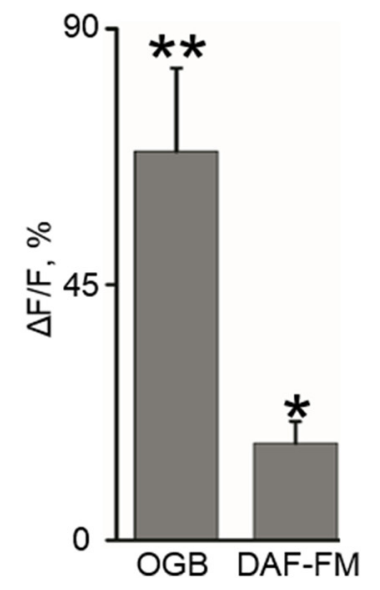

Figure 3. Mechanisms underlying glutamate-induced BBB opening. $A$, Change in the permeability of vessels under different experimental conditions: cortical glutamate application (1 $\mathrm{mm}, \mathrm{glut}$ ), NMDA application (1 mM, NMDA), the addition of D-AP-5 (0.05 mM, glut + D-AP5), and ACSF exposure only (ACSF). B, PCLM (Cellvizio Dual Band; Mauna Kea Technologies) of a rat neocortex, after intravenous injection of EB (see Materials and Methods) and topical application of the calcium indicator OGB (see Materials and Methods). Calcium signal was assessed in the vicinity of microvasculature (white dashed line). C, PCLM of the rat neocortex after intravenous injection of EB and topical application of DAF-FM. N0 signal was assessed in the vicinity of microvasculature. $\boldsymbol{D}$, Rise in calcium signal (OGB) is shown after the drop application of glutamate (1 mM). $\boldsymbol{E}$, Rise in NO signal (DAF-FM) is shown after the drop application of glutamate (1 mM). $\boldsymbol{F}$, Mean calcium and N0 signal (OGB and DAF-FM, respectively) shift in response to glutamate drop application at $1 \mathrm{~mm} .{ }^{*} p<0.05,{ }^{* *} p<0.01$.

tion of tissue oxygen ruled out ischemia in 4-AP/PTX-treated cortices as the cause for barrier dysfunction.

\section{Excessive glutamate release enhances vascular permeability} Hypersynchronization and activation of large neuronal populations is associated with a massive release of the excitatory neurotransmitter glutamate(Bradford, 1995). In cultured brain endothelial cells, the expression of glutamate receptors has been reported (Krizbai et al., 1998; Sharp et al., 2003; András et al., 2007), and exposure to glutamate (1 mM) resulted in NMDA receptor (NMDA-R)-mediated reduction in the levels and cellular redistribution of the tight junction protein occludin, as well as in lower electrical resistance (Sharp et al., 2003; András et al., 2007). To test the hypothesis that excess glutamate mediates BBB dysfunction in vivo, we directly perfused the cortex of anesthetized rats (single dose of ketamine and xylazine, followed by in-

\section{$\leftarrow$}

(Figure legend continued.) of recurrent seizures. $\boldsymbol{F}$, Averaged change in BBB permeability during seizures. $\mathbf{G}$, Permeability maps in response to the application of glutamate for $30 \mathrm{~min}$ $\left(+\right.$ glut $\left.1 \mathrm{~mm}, 30^{\prime}\right) . \boldsymbol{H}$, Dose response showing a gradual change in the permeability of vessels attributable to increased concentrations of glutamate $(1 \mathrm{~mm}, p=0.02, n=9)$. ${ }^{*} p<0.05$. haled isoflurane to minimize NMDA-R antagonism by ketamine; Bankstahl et al., 2008) with increasing concentrations of glutamate (0.01-1 mM). To exclude indirect effects of glutamate via neuronal activation, we blocked neuronal firing and main excitatory and inhibitory GABAergic synaptic transmission using TTX, CNQX, and PTX, respectively. ECoG was recorded simultaneously to confirm reduction in neuronal activity and to exclude the induction of seizures under these experimental conditions (data not shown). Local exposure of the neocortex to glutamate increased vessel permeability in a dose-dependent manner that reached significance at $1 \mathrm{~mm}(18.15 \pm 5.9 \%, n=9$, $p=0.02$, Wilcoxon; Figs. $2 G, H, 3 A)$. Glutamate application was not accompanied by a significant change in vessel diameter (3.12 $\pm 2.24 \%, p=0.16$, Wilcoxon; data not shown).

To test whether the increase in endothelial permeability was attributed to NMDA-R, experiments were repeated with cortical perfusion of NMDA ( $1 \mathrm{~mm}$ ) and with glutamate in the presence of the NMDA-R antagonist D-AP-5 $(50 \mu \mathrm{M})$. Although NMDA, similar to glutamate, increased vessel permeability (18.44 \pm $7.58 \%, n=5, p=0.04$, Wilcoxon; Fig. $3 A$ ), in the presence of D-AP-5, glutamate had no effect on vessel permeability $(-3.81 \pm$ $4.34 \%, n=5, p=0.22$, Wilcoxon; Fig. $3 A$ ). In control experi- 
A

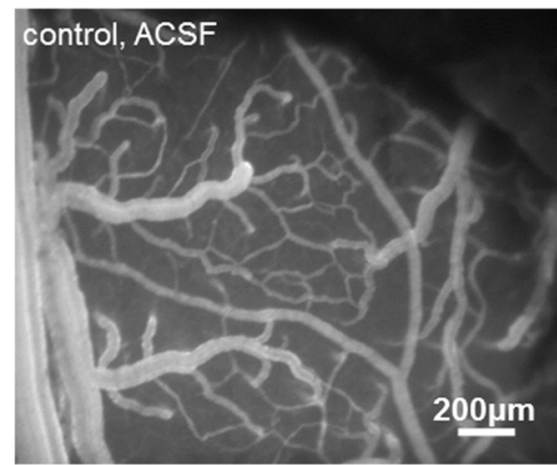

B

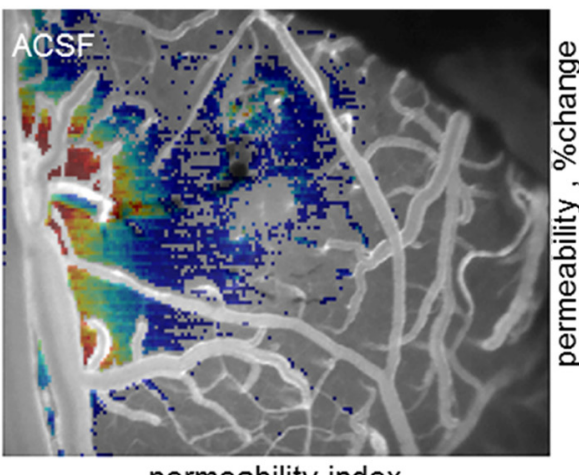

permeability index

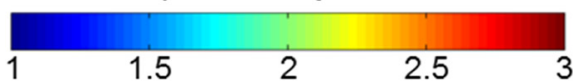

Figure 4. BBB disruption in the peri-ischemic cortex is prevented by the NMDA-R antagonist D-AP-5. $\boldsymbol{A}$, The development of a photothrombosis (PT; see Materials and Methods) as imaged using intravital microscopy after the injection of NaFlu (red arrow indicates damaged vasculature). Increased vessels' permeability (NaFlu leakage) is observed in the peri-ischmic cortex at 60 min follow-up (PT 60', ACSF). $\boldsymbol{B}$, The peri-infarct. Perfused cortex with abnormal permeability is color coded. $\boldsymbol{C}$, Averaged percentage increase in permeability in the peri-infarct cortex at 30 and $60 \mathrm{~min}$ after PT shows a marked increase in permeability in control (ACSF) rats ( $n=9, p=0.008$, Wilcoxon) compared with a nonsignificant change in animals exposed to PT in the presence of the NMDA-R antagonist D-AP-5 ( $n=7, p=0.13$, Wilcoxon). ${ }^{* *} p<0.01$.

ments, brains were exposed to ACSF for 60-120 min, and no significant change in permeability was measured, excluding a time-dependent increase in permeability ("ACSF," $-5.11 \pm$ $3.07 \%, n=16, p=0.7$, Wilcoxon; Fig. $3 A$ ). Because NMDA-Rs conduct calcium ions, we used the calcium-sensitive fluorophore OGB (Fig. 3B, see Materials and Methods) to follow changes in calcium levels in the close surroundings of microvasculature in response to drop application of glutamate (0.01-1 mM). Using image processing of PCLM, we confirmed a long-lasting (12.5 \pm $1.3 \mathrm{~s}$ ) increase in endothelial intracellular calcium after a drop application of glutamate $(n=5, p<0.01$, Wilcoxon; Fig. $3 D, F)$. These findings suggest that, even in the absence of neuronal firing, exposure of brain microvasculature to glutamate results in NMDA-R-mediated increase in intracellular calcium and permeability. Increased intracellular calcium within brain endothelium has been shown to activate NO synthase that generates the free radical NO (De Bock et al., 2013). NO activates guanylyl cyclase, leading to the production of cyclic guanosine monophosphate, cytoskeletal reorganization, and reorganization of tight junction proteins (De Bock et al., 2013). Therefore, we measured NO using the fluorescent sensor DAF-FM. Glutamate drop application ( $1 \mathrm{~mm}$, in the presence of neuronal blockers) induced a significant increase in $\mathrm{NO}$ around microvessels $(17.03 \pm 3.85 \%, n=3$, $p=0.03$, Wilcoxon; Fig. $3 C, E, F)$.

\section{Therapeutic implications: preclinical studies}

Because excess glutamate release is a hallmark of hypoxic-ischemic injuries (Benveniste et al., 1984; Rothman and Olney, 1986; Nishizawa, 2001) and because the dynamic progression of BBB dysfunction has been characterized in the rat cerebral cortex stroke photothrombosis model (Schoknecht et al., 2014), we tested the hypothesis that blocking NMDA-R activation could reduce $\mathrm{BBB}$ breakdown in the peri-ischemic brain. A focal ischemic lesion was induced under ketamine/xylazine anesthesia by photothrombosis after an injection of RB (Watson et al., 1987; Prager et al., 2010; Schoknecht et al., 2014; Fig. $4 A$ ) in the presence or absence of the specific NMDA-R blocker D-AP-5. The spatial progression of BBB dysfunction in the peri-ischemic region was significantly reduced in the presence of D-AP-5 at 30 and $60 \mathrm{~min}$ after clot induction $(p=0.03$, Mann-Whitney; Fig. 4B,C). Another therapeutic implication of our findings is the potential induction of BBB opening for drug delivery. We thus tested whether the release of glutamate associated with synchronous neuronal activation using rTMS could increase barrier permeability and facilitate drug delivery into the brain. After $1 \mathrm{~Hz}$ stimulation to the anesthetized (ketamine/xylazine) rat, vascular permeability was significantly increased (18.52 \pm $6.54 \%, n=11, p=0.006$, Wilcoxon; Fig. $5 A, B)$. This effect was milder and did not reach a significant level with $10 \mathrm{~Hz}$ stimulation $(6.93 \pm 4.22 \%, n=8, p=0.21$, Wilcoxon; Fig. $5 B$ ). No change in permeability was observed after sham stimulation ("sham," $0.8 \pm$ $1.86 \%, n=14, p=0.59$, Wilcoxon; Fig. $5 B$ ). That rTMS effect is mediated through neuronal activation was confirmed by showing that, in the presence of neuronal activity and synaptic transmission blockers, rTMS failed to increase vascular permeability $(2.66 \pm 2.33 \%, n=6, p=0.92$, Wilcoxon; Fig. $5 B)$. To test whether rTMS-induced increase in permeability may be used for expediting drug delivery into the brain, we tested the effect of peripherally administered penicillin on neuronal activity. Penicillin is a $\mathrm{GABA}_{\mathrm{A}}$ receptor antagonist, and, when directly applied to the brain, it blocks inhibitory transmission and increases network excitability and often induces seizures (Elger and Speckmann, 1983). However, in the presence of an intact BBB, peripheral administration of low dose of penicillin in the rat has only a moderate effect on brain activity (Fishman, 1966; Fariello, 1976). We thus used ECoG recordings in the presence of the intravenous administration of penicillin as a functional measure for penicillin brain penetration. Whereas under control conditions penicillin only mildly elevated ECoG power $(10-40 \mathrm{~Hz}$, $140.29 \pm 62.2 \%, n=5$ ), repeated injection of the drug after $1 \mathrm{~Hz}$ rTMS stimulation protocol resulted in a significantly increased ECoG power $(10-40 \mathrm{~Hz}, 334.96 \pm 185.77 \%, n=5, p=0.04$, Wilcoxon; Fig. 5C,D). A second penicillin injection with no TMS did not result in increased ECoG power $(-37.97 \pm 167.07 \%$ 
A

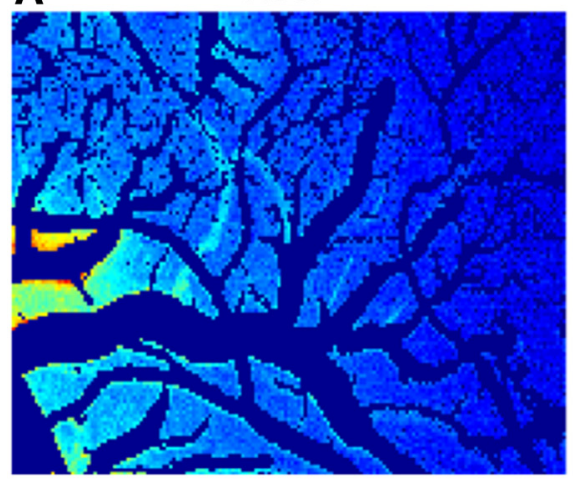

C control

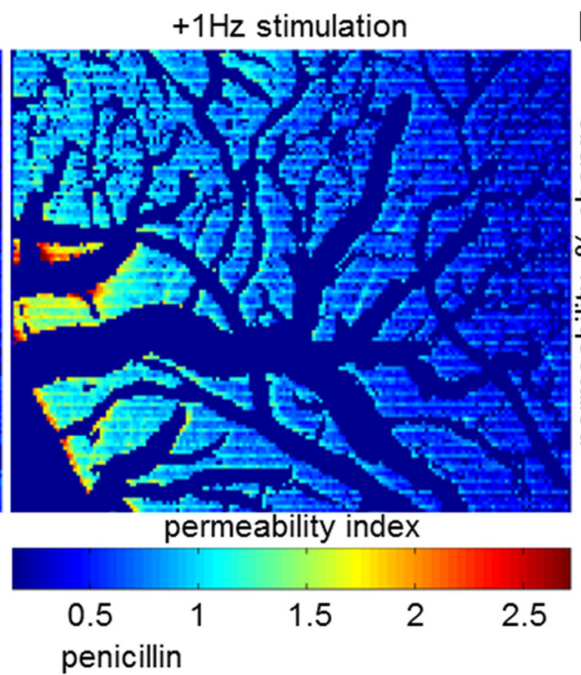

penicillin
B

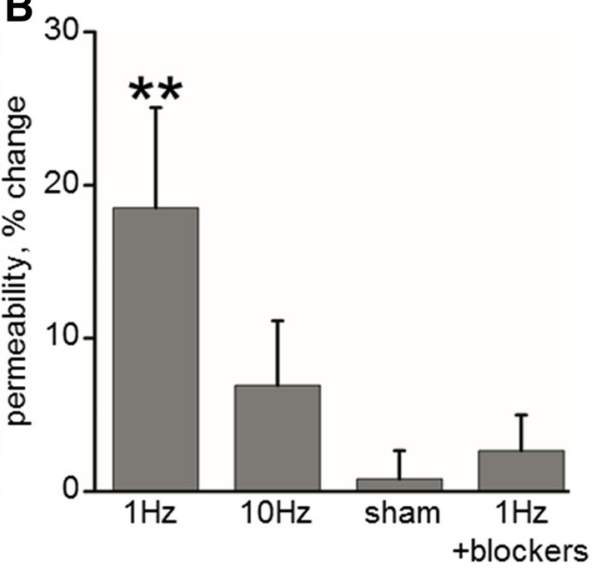

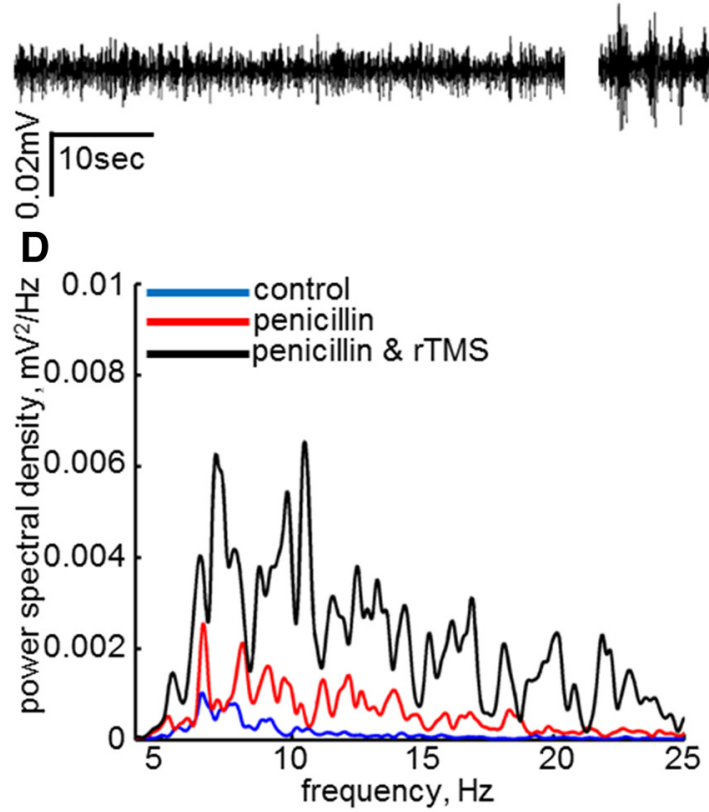
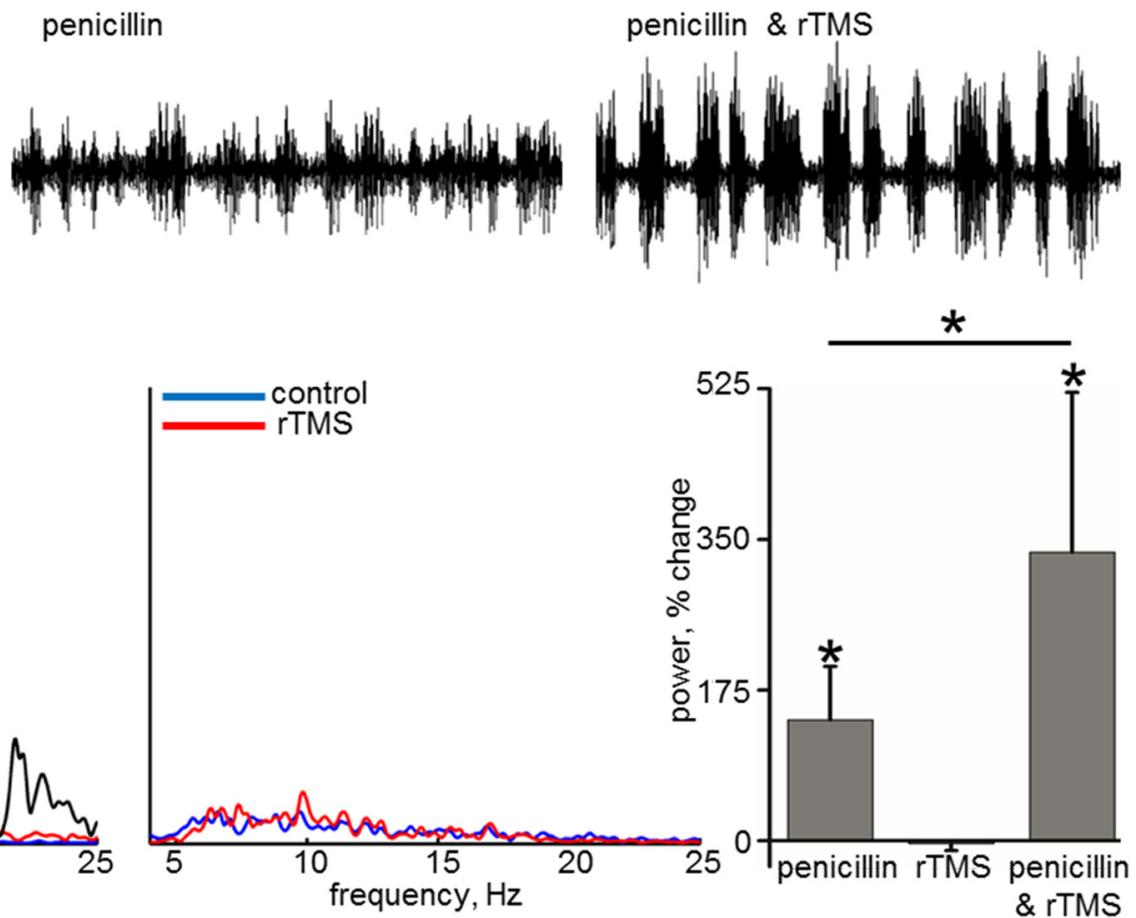

Figure 5. rTMS induces BBB opening and facilitates drug delivery to the rat cortex. $A$, Spatial permeability mapping showing the effect of $1 \mathrm{~Hz}$ rTMS on BBB permeability. $\boldsymbol{B}$, Averaged percentage change in the permeability of vessels after rTMS at $1 \mathrm{~Hz}(p=0.006, n=11)$ and $10 \mathrm{~Hz}$ stimulation. Note the lack of permeability change in control experiments ("sham") and in the presence of the $\mathrm{Na}^{+}$channel blocker TTX and synaptic transmission blockers (1Hz+ blockers). C, ECOG recordings in an anesthetized rat before (control, left), after intravenous administration of penicillin ( 0.833 $\mathrm{MU} / \mathrm{kg}$, penicillin, middle), and with the combination of intravenous penicillin and rTMS (penicillin \& rTMS, right). The administration of penicillin generates a rise in amplitude and frequency of brain activity, which was intensified, when followed by $r T M S$. $D$, Spectral analysis of ECOG recordings under the same experimental conditions. Bar graph shows the mean ( \pm SEM) of percentage change in signal power $(10-40 \mathrm{~Hz}, n=5, p=0.04) .{ }^{*} p<0.05,{ }^{* *} p<0.01$.

from the first injection, $n=4$ ), ruling out that the observed effect was attributable to repeated drug injections. rTMS on its own was not associated with enhanced brain activity $(-3.57 \pm 8.11 \%$ at $10-40 \mathrm{~Hz}, n=3$; Fig. $5 \mathrm{D}$ ), ruling out the possibility that rTMS underlies the observed lasting increase in neuronal excitability. These experiments suggest that rTMS-induced BBB opening is associated with facilitated delivery of penicillin to the neural tissue.

rTMS increases BBB permeability in human patients

Based on our preclinical experiments, we performed a pilot clinical study designed to examine the effects of rTMS on barrier integrity in 15 patients with malignant glial tumors (GBM, grade IV). All patients participated in our study at least 6 months after tumor resection (patient characteristics are listed in Table 1).
dTMS $(1 \mathrm{~Hz}$ ) was applied using standard protocols (Zangen and Hyodo, 2002; Zangen et al., 2005; Roth et al., 2007) directed to the peritumoral brain region (see Materials and Methods). None of the patients presented adverse events attributable to stimulation. BBB permeability was quantified, immediately after stimulation, using DCE-MRI (Fig. 6; see Materials and Methods; Chassidim et al., 2013, 2015; Veksler et al., 2014) Dynamic T1 data was calculated and a linear curve was fitted (seven time points, 3-21 min after entry to the scanner), generating a slope value for each voxel ("slope map"; Fig. 6A-C). A negative slope indicated normal washout of the contrast agent from the vascular compartment, whereas a positive slope suggested accumulation of the contrast agent in areas with absent or compromised BBB. Method validation was achieved by demonstration of the following: (1) positive slope measured in tissues lacking BBB (e.g., extracranial muscle); 
A

B

C
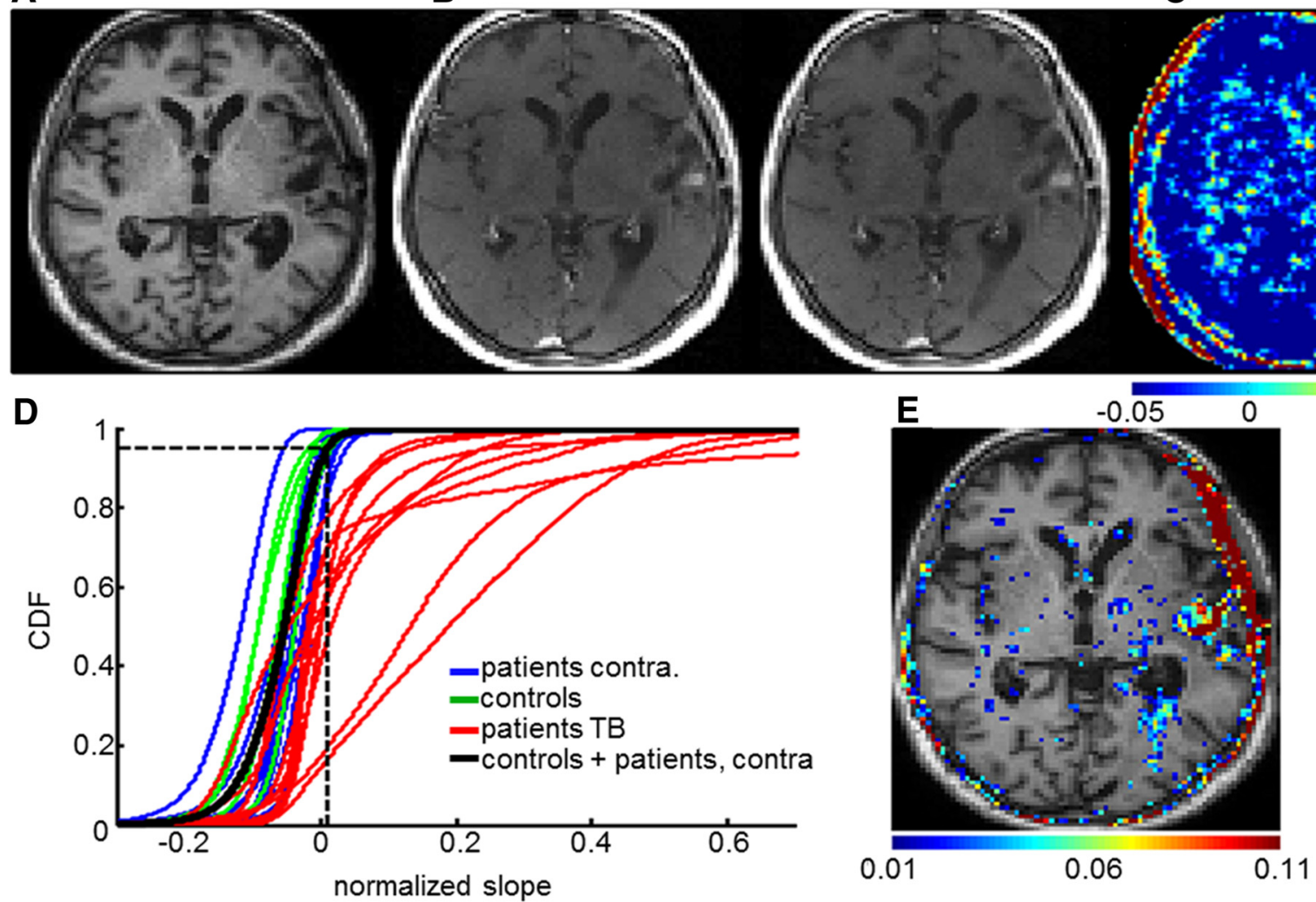

Figure 6. BBB permeability assessment with DCE-MRI analysis in human subjects. $\boldsymbol{A}$, T1-weighted MRI scan of a patient after tumor resection. $\boldsymbol{B}$, First and seventh dynamic scans. $\boldsymbol{C}$, Normalized slope map indicating BBB permeability. D, CDFs of the normalized slope values of four control subjects (whole brain, green) and 10 patients after tumor resection in the contralateral hemisphere to the tumor (blue) and the tumor bed (TB, red). The total CDF of controls + contralateral hemisphere to the tumor is in black. Dashed lines indicate the global threshold value of 0.0109, derived from the 95th percentile of the total CDF. $\boldsymbol{E}$, Voxels with ST slope values.

(2) positive slope measured in areas of tumors and surrounding tissue; and (3) negative slope measured in major blood vessels, such as the venous sinuses. Threshold for "normal permeability" was calculated as the 95th percentile of the CDF of the tissuemasked slope maps of the hemisphere contralateral to the tumor (after sham stimulation) and of both hemispheres for the control group (Fig. 6D; see Materials and Methods). Permeability change was compared between two DCE-MRI scans performed after real and sham dTMS, randomly assigned within $1 \mathrm{~d}$ of each other. Experimenters and patients were blinded to the choice of real versus sham. In 10 of 15 patients, we found a significant increase in brain enhancement slope values after real compared with sham dTMS, indicating increased barrier permeability to Gd-based contrast agent after dTMS (Fig. 7A). Enhancement maps displaying the percentage difference between real and sham sessions show that maximal difference was found in the stimulated tumor bed region. However, significant changes were also observed in the peritumoral and ipsilateral brain, as well as in the contralateral hemisphere (Fig. $7 B-E$ ). In the 10 patients showing effect of stimulation, a right shift of the CDF of permeability values was observed compared with averaged values after sham stimulation, indicating above-normal vascular permeability (Fig. 7F). Overall, increased permeability was found in the tumor bed in nine subjects and in the peritumoral area in seven subjects, and in eight subjects, increased permeability was also found in the more distant ipsilateral and contralateral hemispheres.

\section{Discussion}

The BBB is the hallmark of normal brain vascularization, enabling the unique extracellular neuronal environment essential for its proper function. Vascular pathology and dysfunctional $\mathrm{BBB}$ are common in brain diseases, particularly described in ischemic and traumatic brain injuries (Prager et al., 2010; Schoknecht et al., 2014) but also in aging and neurodegenerative disorders (Mecocci et al., 1991; Montagne et al., 2015), as well as in peripheral diseases affecting the brain (e.g., hypertension and diabetes mellitus; Mooradian, 1997). Increased endothelial permeability to serum proteins has been found to induce an astrocytic transformation associated with neuroinflammation and impaired control of the extracellular milieu, neuronal hyperexcitability, synaptogenesis, and pathological plasticity (Cacheaux et al., 2009; David et al., 2009; Weissberg et al., 2015). Experimental and clinical evidence thus support the notion that a compromised BBB may be associated with dysfunction of the neurovascular network, cognitive and emotional impairments (Montagne et al., 2015), seizures and epilepsy (Friedman, 2011), and neurodegeneration (Zlokovic, 2008), thus highlighting vascular integrity as a target for treatment. However, there is lack of knowledge regarding the mechanisms of $\mathrm{BBB}$ opening under disease conditions and no therapeutics available to modulate BBB integrity. For decades, the intact $\mathrm{BBB}$, as a major obstacle for drug delivery into the brain, has been the target of research and clinical trials aiming to transiently increase its permeability. In the present study, we show that high concentrations of glutamate, the major excitatory brain neurotransmitter, directly modulate vascular permeability. We further demonstrate using confocal microscopy that glutamate enhances calcium influx and NO levels within or adjacent to microvascular structures, leading to increased vascular permeability through activation of NMDA-R. We demonstrate two 
A

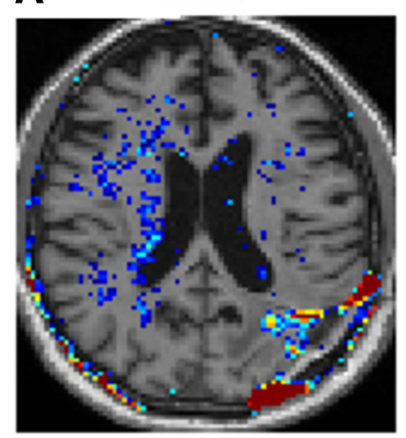

C

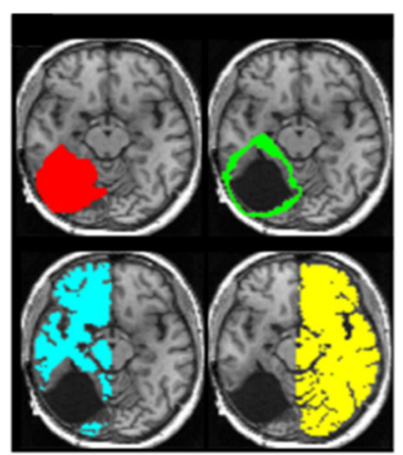

TMS

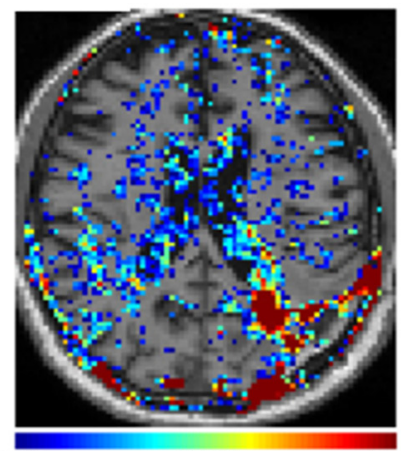

0.06
B

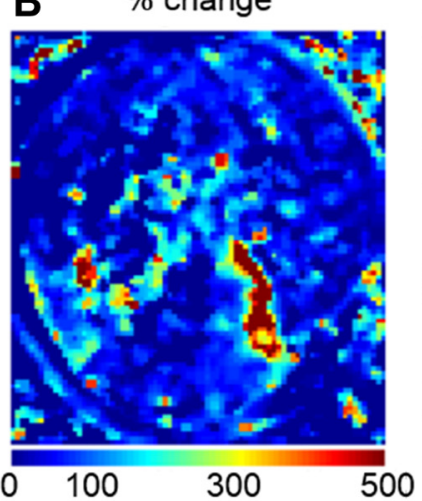

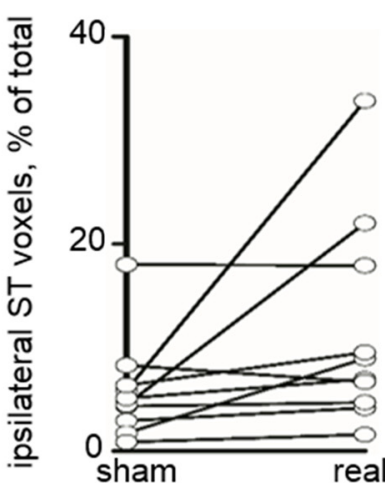

$\mathbf{F}$

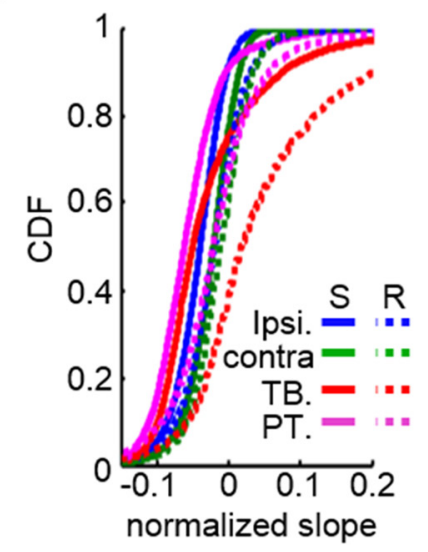

Figure 7. dTMS induces increase in BBB permeability in patients with malignant glial tumors. $A, B B B$ permeability maps superimposed on T1 brain MR images in a representative patient after sham and TMS sessions. Color-coded voxels represent only those with abnormally high slope (permeability) values (ST; see Materials and Methods). $\boldsymbol{B}$, Percentage of change in apparent permeability values for the patient shown in $\boldsymbol{A}$. Graphs showing percentage of voxels within the ipsilateral hemisphere with abnormally high permeability after sham and real dTMS. C, Brains were manually segmented (left) to subregions reflecting the tumor bed (TB, red), peri-tumoral brain (PT, green), and ipsilateral (ipsi, blue) and contralateral (contra, yellow) hemispheres. $\boldsymbol{D}$, Averaged percentage change in permeability (slope values) in real versus sham stimulation was calculated for each subregion (tumor bed, $p=0.01$; peri-tumor, $p=0.05 ;$ ipsilateral, $p=0.01$; contralateral, $p=0.009$ ). Note that, although in all regions TMS had a significant effect, maximal change was found in the tumor bed ( $n=10$ patients). $\boldsymbol{E}$, Percentage change in the number of ST voxels (reflecting abnormally high permeability; see Materials and Methods) is plotted for each subregion. $\boldsymbol{F}$, CDFs of apparent permeability (slope) values in the different subregions under sham (S) and real (R) dTMS for 10 patients. Note the shift of the curves to the right indicating increased number of voxels with high permeability values, in all regions, most prominently in the tumor bed. ${ }^{*} p<0.05$, ${ }^{* *} p<0.01$.

novel therapeutic implications of our findings: (1) that increased BBB permeability in the peri-ischemic brain (a common finding in stroke patients and a risk factor for hemorrhagic complication in the presence of antithrombotic treatment) can be prevented using NMDA-R antagonists; and (2) that repeated stimulation of large groups of neurons increases BBB permeability in both experimental animals and in patients with malignant brain tumors.

Consistent with previous reports (Librizzi et al., 2012; van Vliet et al., 2014), we show that the induction of seizures in vivo is associated with an increase in vessel diameter and permeability to both low- and high-molecular-weight substances (Fig. 2). BBB dysfunction was not associated with a significant decrease in tissue oxygen levels, and, because of neurovascular coupling, tissue oxygen levels rapidly increased above baseline, ruling out tissue hypoxia as a cause for the rapid increase in endothelial permeability during seizures. Prolonged or frequently recurring seizures, as well as ischemic stroke and traumatic brain injury, are associated with increased concentrations of extracellular glutamate (>50-fold increase and in the 0.1-1 mM range; Benveniste et al., 1984; Rothman and Olney, 1986; Bradford, 1995; Nishizawa, 2001; Parfenova et al., 2006). Our data, showing that a greater TMS-mediated increase in permeability is prevented when neu- ronal activity is blocked, but not when glutamate is applied, suggests that neuronal release of glutamate is targeting a nonneuronal target. Interestingly, in the absence of neuronal activity, glutamate did not induce an increase in vessel diameter, suggesting different mechanisms underlying the coupling between neuronal activity to vascular diameter response and permeability. The observations that direct application of NMDA similarly enhances permeability and that permeability increase is blocked in the presence of NMDA-R blockers (Fig. $3 A$ ) indicate that the effect of glutamate is mediated by NMDA-R. Whether intracellular calcium increase is required for enhanced permeability is not known. Preventing intracellular calcium elevation using calcium chelators is not feasible in vivo because of massive vasoconstriction and ischemia (data not shown). However, the observed increased intracellular calcium and NO in the proximity of microvasculature in response to glutamate is consistent with in vitro data showing that NMDA-mediated increased endothelial permeability is dependent on increased intracellular calcium within endothelial cells that leads to free radical formation (Krizbai et al., 1998; Sharp et al., 2003, 2005). Nevertheless, we cannot rule out a role for components of the neurovascular unit in close proximity to endothelial cells, including astrocytes and pericytes (Car- 
mignoto and Gómez-Gonzalo, 2010). The intracellular signaling leading to enhanced permeability is also not clear and may involve reorganization (De Bock et al., 2013) and/or downregulation of tight junction elements (András et al., 2007). The latter seems unlikely with the relatively short time delay between insult (seizure/stroke) and enhanced permeability. Modulation of transcellular transport mechanisms (e.g., Intercellular adhesion molecule mediated; Yang et al., 2005) may also be involved. Cortical injury and associated glutamate release has been shown to induce spreading depolarizations. Interestingly, spreading depolarization has been associated with BBB opening through the upregulation of matrix metallopeptidase 9 (Gursoy-Ozdemir et al., 2004). Although spreading depolarization can be induced even in the presence of TTX (Aitken et al., 1991) and cannot be ruled out in our experiments (because ECoG recordings were performed with a bandpass of $10-40 \mathrm{~Hz}$ ), it is unlikely that glutamate application in the concentration range used in the present study induced spreading depolarization. In addition, the rapid increase in permeability we observed $(<30 \mathrm{~min})$ in the presence of seizures, photothrombosis, or glutamate application is much shorter than reported for spreading depolarization (3-6 h; Gursoy-Ozdemir et al., 2004).

Brain insults, including hypoxic-ischemic or traumatic injuries, were shown to be associated with synchronous neuronal hyperexcitability and elevated extracellular glutamate in both animal models and humans (Benveniste et al., 1984; Rothman and Olney, 1986; Nishizawa, 2001). Interestingly, although NMDA-R antagonists were consistently shown to be neuroprotective in animal models of brain injuries (Rao et al., 2001; Miguel-Hidalgo et al., 2002; Huang et al., 2015), their effects on brain vasculature have never been carefully tested. We propose that at least part of the protecting effect of NMDA-R blockers may be attributable to their therapeutic effect to reduce BBB breakdown within the periischemic/peri-injured brain. However, other non-neuronal mechanisms, including downregulation of cytokines and reduced injury-induced inflammation (Jander et al., 2000), may contribute to the observed effect. The failure of NMDA-R antagonists as neuroprotectants in clinical trials (Morris et al., 1999; Ikonomidou and Turski, 2002) might be attributable to variability between patients in the extent of BBB damage (Friedman et al., 2014). This testable hypothesis calls for BBB imaging in patients with brain insults and follow-up of NMDA-R effects on vascular integrity and clinical outcome in specific subgroups of patients.

As part of this study, we used recently established DCE-MRI protocols (Weissberg et al., 2014) to quantify changes in BBB permeability in patients after sham or real TMS stimulation with the goal to validate and quantify (for the first time) increased barrier permeability in response to manipulation. Previous attempts to increase drug delivery included intra-arterial administration of mannitol in combination with a chemotherapeutic agent. This approach has not become a routine practice mainly because of poor patient tolerance, difficulty to perform repeatedly, and lack of confidence in treatment efficacy (Phurrough et al., 2007). We recruited patients with malignant brain tumors to test the clinical feasibility and potential realization of our animal data. Patients with GBM were chosen given the medical need for enhanced delivery of chemotherapeutics into the brain. For the first time, we report the use of quantitative DCE-MRI to confirm a therapeutic modulation of vascular permeability in an individual patient. TMS may thus become the first approach for a noninvasive and safe transient BBB opening for drug delivery. Nevertheless, human data are complex and can indeed be interpreted in different ways. The responsiveness of some patients and not others to stimulation could have resulted from factors associated with tumor-related changes in microvasculature, other treatments (e.g., radiation; Fink et al., 2012), and/or the patients' medical history and/or general condition. The observation that stimulation-induced permeability increase was larger in (and in the surrounding of) the tumor site, supports tumor-related changes, including altered vascularization, neovascularization (Baker et al., 2014; Weber et al., 2014), and/or inflammatory environment (Raychaudhuri et al., 2007). Interestingly, malignant glioma cells were shown to release glutamate that has been associated with neuronal toxicity and tumor expansion (for review, see Sontheimer, 2008). Such release is expected to increase baseline glutamate levels in the peri-tumoral brain that may be sufficient for abnormal increase in permeability and enhanced response to stimulation in the vicinity of the tumor. Importantly, permeability increase (to a lower extent) was found significant even in regions distant from the tumor bed (including the contralateral hemisphere), suggesting that stimulus affected normal brain vessels as well. Overall, the results from this pilot clinical study stress the translational potential and feasibility of stimulusinduced transient BBB opening in the clinical scenario. Future preclinical studies and clinical trials are awaited to test TMS effects on the delivery of specific chemotherapeutics and patients' outcome. Additionally, the features of TMS-induced BBB opening have yet to be fully examined with regards to safety, specifically the risk of seizures, being the primary concern (Rossi et al., 2009), in patients with brain tumors (van Breemen et al., 2007).

In summary, we present a novel, neuronal-activity mediated, NMDA-R-dependent mechanism for the modulation of the permeability of brain vasculature. We propose that this mechanism may be exploited for facilitating BBB closure in neurological disorders and opening in tumor patients to enhance drug delivery.

\section{References}

Abbott NJ, Rönnbäck L, Hansson E (2006) Astrocyte-endothelial interactions at the blood-brain barrier. Nat Rev Neurosci 7:41-53. CrossRef Medline

Aitken PG, Jing J, Young J, Somjen GG (1991) Ion channel involvement in hypoxia-induced spreading depression in hippocampal slices. Brain Res 541:7-11. CrossRef Medline

András IE, Deli MA, Veszelka S, Hayashi K, Hennig B, Toborek M (2007) The NMDA and AMPA/KA receptors are involved in glutamate-induced alterations of occludin expression and phosphorylation in brain endothelial cells. J Cereb Blood Flow Metab 27:1431-1443. CrossRef Medline

Baker GJ, Yadav VN, Motsch S, Koschmann C, Calinescu AA MY, CameloPiragua SI, Orringer D, Bannykh S, Nichols WS, deCarvalho AC, Mikkelsen T, Castro MG, Lowenstein PR (2014) Mechanisms of glioma formation: iterative perivascular glioma growth and invasion leads to tumor progression, VEGF-independent vascularization, and resistance to antiangiogenic therapy. Neoplasia 16:543-561. CrossRef Medline

Bankstahl JP, Hoffmann K, Bethmann K, Löscher W (2008) Glutamate is critically involved in seizure-induced overexpression of P-glycoprotein in the brain. Neuropharmacology 54:1006-1016. CrossRef Medline

Benveniste H, Drejer J, Schousboe A, Diemer NH (1984) Elevation of the extracellular concentrations of glutamate and aspartate in rat hippocampus during transient cerebral ischemia monitored by intracerebral microdialysis. J Neurochem 43:1369-1374. CrossRef Medline

Bradford HF (1995) Glutamate, GABA and epilepsy. Prog Neurobiol 47: 477-511. CrossRef Medline

Brown RC, Davis TP (2002) Calcium modulation of adherens and tight junction function: a potential mechanism for blood-brain barrier disruption after stroke. Stroke 33:1706-1711. CrossRef Medline

Cacheaux LP, Ivens S, David Y, Lakhter AJ, Bar-Klein GS, Shapira M, Heinemann U, Friedman A, Kaufer D (2009) Transcriptome profiling reveals TGF-beta signaling involvement in epileptogenesis. J Neurosci 29:89278935. CrossRef Medline

Carmignoto G, Gómez-Gonzalo M (2010) The contribution of astrocyte 
signalling to neurovascular coupling. Brain Res Rev 63:138-148. CrossRef Medline

Chassidim Y, Veksler R, Lublinsky S, Pell GS, Friedman A, Shelef I (2013) Quantitative imaging assessment of blood-brain barrier permeability in humans. Fluids Barriers CNS 10:9. CrossRef Medline

Chassidim Y, Vazana U, Prager O, Veksler R, Bar-Klein G, Schoknecht K, Fassler M, Lublinsky S, Shelef I (2015) Analyzing the blood-brain barrier: The benefits of medical imaging in research and clinical practice. Semin Cell Dev Biol 38:43-52. CrossRef Medline

David Y, Cacheaux LP, Ivens S, Lapilover E, Heinemann UK, Kaufer D, Friedman A (2009) Astrocytic dysfunction in epileptogenesis: consequence of altered potassium and glutamate homeostasis? J Neurosci 29: 10588-10599. CrossRef Medline

Davies DC (2002) Blood-brain barrier breakdown in septic encephalopathy and brain tumours. J Anat 200:639-646. CrossRef Medline

De Bock M, Wang N, Decrock E, Bol M, Gadicherla AK, Culot M, Cecchelli R, Bultynck G, Leybaert L (2013) Endothelial calcium dynamics, connexin channels and blood-brain barrier function. Prog Neurobiol 108:1-20. CrossRef Medline

Elger CE, Speckmann EJ (1983) Experimental Section: Penicillin-induced epileptic foci in the motor cortex: vertical inhibition. Electroencephalogr Clin Neurophysiol 56:604-622. CrossRef Medline

Fariello RG (1976) Parenteral penicillin in rats: an experimental model of multifocal epilepsy. Epilepsia 17:217-222. CrossRef Medline

Fink J, Born D, Chamberlain MC (2012) Radiation necrosis: relevance with respect to treatment of primary and secondary brain tumors. Curr Neurol Neurosci Rep 12:276-285. CrossRef Medline

Fishman RA (1966) Blood-brain and csf barriers to penicillin and related organic acids. Arch Neurol 15:113-124. CrossRef Medline

Friedman A (2011) Blood-brain barrier dysfunction, status epilepticus, seizures, and epilepsy: a puzzle of a chicken and egg? Epilepsia 52:19-20. CrossRef Medline

Friedman A, Bar-Klein G, Serlin Y, Parmet Y, Heinemann U, Kaufer D (2014) Should losartan be administered following brain injury? Expert Rev Neurother 14:1365-1375. CrossRef Medline

Gersner R, Kravetz E, Feil J, Pell G, Zangen A (2011) Long-term effects of repetitive transcranial magnetic stimulation on markers for neuroplasticity: differential outcomes in anesthetized and awake animals. J Neurosci 31:7521-7526. CrossRef Medline

Gursoy-Ozdemir Y, Qiu J, Matsuoka N, Bolay H, Bermpohl D, Jin H, Wang X, Rosenberg GA, Lo EH, Moskowitz MA (2004) Cortical spreading depression activates and upregulates MMP-9. J Clin Invest 113:1447-1455. CrossRef Medline

Huang CY, Wang LC, Wang HK, Pan CH, Cheng YY, Shan YS, Chio CC, Tsai KJ (2015) Memantine alleviates brain injury and neurobehavioral deficits after experimental subarachnoid hemorrhage. Mol Neurobiol 51: 1038-1052. CrossRef Medline

Ikonomidou C, Turski L (2002) Why did NMDA receptor antagonists fail clinical trials for stroke and traumatic brain injury? Lancet Neurol 1:383386. CrossRef Medline

Jander S, Schroeter M, Stoll G (2000) Role of NMDA receptor signaling in the regulation of inflammatory gene expression after focal brain ischemia. J Neuroimmunol 109:181-187. CrossRef Medline

Krizbai IA, Deli MA, Pestenácz A, Siklós L, Szabó CA, András I, Joó F (1998) Expression of glutamate receptors on cultured cerebral endothelial cells. J Neurosci Res 54:814-819. CrossRef Medline

Librizzi L, Noè F, Vezzani A, de Curtis M, Ravizza T (2012) Seizure-induced brain-borne inflammation sustains seizure recurrence and blood-brain barrier damage. Ann Neurol 72:82-90. CrossRef Medline

Mecocci P, Parnetti L, Reboldi GP, Santucci C, Gaiti A, Ferri CG, I, Romagnoli M, Cadini D, Senin U (1991) Blood-brain-barrier in a geriatric population: barrier function in degenerative and vascular dementias. Acta Neurol Scand 84:210-213. CrossRef Medline

Miguel-Hidalgo JJ, Alvarez XA, Cacabelos R, Quack G (2002) Neuroprotection by memantine against neurodegeneration induced by beta-amyloid(1-40). Brain Res 958:210-221. CrossRef Medline

Montagne A, Barnes SR, Sweeney MD, Halliday MR, Sagare AP, Zhao Z, Toga AW, Jacobs RE, Liu CY, Amezcua L, Harrington MG, Chui HC, Law M, Zlokovic BV (2015) Blood-brain barrier breakdown in the aging human hippocampus. Neuron 85:296-302. CrossRef Medline

Mooradian AD (1997) Central nervous system complications of diabetes mellitus-a perspective from the blood-brain barrier. Brain Res Rev 23: 210-218. CrossRef Medline

Morris GF, Bullock R, Marshall SB, Marmarou A, Maas A, Marshall LF (1999) Failure of the competitive $N$-methyl-D-aspartate antagonist Selfotel (CGS 19755) in the treatment of severe head injury: results of two Phase III clinical trials. J Neurosurg 91:737-743. CrossRef Medline

Morris RG (1989) Synaptic plasticity and learning: selective impairment of learning rats and blockade of long-term potentiation in vivo by the $N$-methyl-D-aspartate receptor antagonist AP5. J Neurosci 9:3040-3057. Medline

Mottaghy FM, Gangitano M, Horkan C, Chen Y, Pascual-Leone A, Schlaug G (2003) Repetitive TMS temporarily alters brain diffusion. Neurology 60: 1539-1541. CrossRef Medline

Narahashi T, Moore JW, Scott WR (1964) Tetrodotoxin blockage of sodium conductance increase in lobster giant axons. J Gen Physiol 47:965-974. CrossRef Medline

Nishizawa Y (2001) Glutamate release and neuronal damage in ischemia. Life Sci 69:369-381. CrossRef Medline

Nitsch C, Hubauer H (1986) Distant blood-brain barrier opening in subfields of the rat hippocampus after intrastriatal injections of kainic acid but not ibotenic acid. Neurosci Lett 64:53-58. CrossRef Medline

Parfenova H, Basuroy S, Bhattacharya S, Tcheranova D, Qu Y, Regan RF, Leffler CW (2006) Glutamate induces oxidative stress and apoptosis in cerebral vascular endothelial cells: contributions of HO-1 and HO-2 to cytoprotection. Am J Physiol Cell Physiol 290:C1399-C1410. CrossRef Medline

Phurrough S, Jacques L, Turner T, Rollins J (2007) Decision memo for blood brain barrier disruption (BBBD) chemotherapy (CAG-00333N). Baltimore: Centers for Medicaid and Medicare Services.

Prager O, Chassidim Y, Klein C, Levi H, Shelef I, Friedman A (2010) Dynamic in vivo imaging of cerebral blood flow and blood-brain barrier permeability. Neuroimage 49:337-344. CrossRef Medline

Rao VL, Dogan A, Todd KG, Bowen KK, Dempsey RJ (2001) Neuroprotection by memantine, a non-competitive NMDA receptor antagonist after traumatic brain injury in rats. Brain Res 911:96-100. CrossRef Medline

Raychaudhuri B, Han Y, Lu T, Vogelbaum MA (2007) Aberrant constitutive activation of nuclear factor $\kappa \mathrm{B}$ in glioblastoma multiforme drives invasive phenotype. J Neurooncol 85:39-47. CrossRef Medline

Rossi S, Hallett M, Rossini PM, Pascual-Leone A (2009) Safety, ethical considerations, and application guidelines for the use of transcranial magnetic stimulation in clinical practice and research. Clin Neurophysiol 120:2008-2039. CrossRef Medline

Roth Y, Padberg F, Zangen A (2007) Transcranial magnetic stimulation of deep brain regions: principles and methods. Transcranial Brain Stimul Treat Psychiatr Disord 23:204-224.

Rothman SM, Olney JW (1986) Glutamate and the pathophysiology of hypoxicischemic brain damage. Ann Neurol 19:105-111. CrossRef Medline

Schoknecht K, Prager O, Vazana U, Kamintsky L, Harhausen D, Zille M, Figge L, Chassidim Y, Schellenberger E, Kovács R, Heinemann U, Friedman A (2014) Monitoring stroke progression: in vivo imaging of cortical perfusion, blood-brain barrier permeability and cellular damage in the rat photothrombosis model. J Cereb Blood Flow Metab 34:1791-1801. CrossRef Medline

Seiffert E, Dreier JP, Ivens S, Bechmann I, Tomkins O, Heinemann U, Friedman A (2004) Lasting blood-brain barrier disruption induces epileptic focus in the rat somatosensory cortex. J Neurosci 24:7829-7836. CrossRef Medline

Sharp CD, Hines I, Houghton J, Warren A, Jackson IV TH, Jawahar A, Nanda A, Elrod JW, Long A, Chi A, Minagar A, Alexander JS (2003) Glutamate causes a loss in human cerebral endothelial barrier integrity through activation of NMDA receptor. Am J Physiol Hear Circ Physiol 285:H2592_ H2598. CrossRef Medline

Sharp CD, Houghton J, Elrod JW, Warren A, Jackson IV TH, Jawahar A, Nanda A, Minagar A, Alexander JS, Christopher D (2005) N-methyl-Daspartate receptor activation in human cerebral endothelium promotes intracellular oxidant stress. Am J Physiol Hear Circ Physiol 3932: 1893-1899. CrossRef Medline

Sontheimer H (2008) A role for glutamate in growth and invasion of primary brain tumors. J Neurochem 105:287-295. CrossRef Medline

Stosiek C, Garaschuk O, Holthoff K, Konnerth A (2003) In vivo two-photon calcium imaging of neuronal networks. Proc Natl Acad Sci U S A 100: 7319-7324. CrossRef Medline 
Tofts PS (1997) Modeling tracer kinetics in dynamic Gd-DTPA MR imaging. J Magn Reson Imaging 7:91-101. CrossRef Medline

Tomkins O, Shelef I, Kaizerman I, Eliushin A, Afawi Z, Misk A, Gidon M, Cohen A, Zumsteg D, Friedman A (2008) Blood-brain barrier disruption in post-traumatic epilepsy. J Neurol Neurosurg Psychiatry 79:774777. CrossRef Medline

Uva L, Trombin F, Carriero G, Avoli M, de Curtis M (2013) Seizure-like discharges induced by 4 -aminopyridine in the olfactory system of the in vitro isolated guinea pig brain. Epilepsia 54:605-615. CrossRef Medline

van Breemen MS, Wilms EB, Vecht CJ (2007) Epilepsy in patients with brain tumours: epidemiology, mechanisms, and management. Lancet Neurol 6:421-430. CrossRef Medline

van Vliet EA, da Costa Araújo S, Redeker S, van Schaik R, Aronica E, Gorter JA (2007) Blood-brain barrier leakage may lead to progression of temporal lobe epilepsy. Brain 130:521-534. CrossRef Medline

Van Vliet EA, Otte WM, Gorter JA, RM Dijkhuizen RM, Wadman WJ (2014) Longitudinal assessment of blood-brain barrier leakage during epileptogenesis in rats. A quantitative MRI study. Neurobiol Dis 63:74-84. CrossRef Medline

Veksler R, Shelef I, Friedman A (2014) Blood-brain barrier imaging in human neuropathologies. Arch Med Res 45:646-652. CrossRef Medline

Watson BD, Dietrich WD, Prado R, Ginsberg MD (1987) Argon laserinduced arterial photothrombosis characterization and possible application to therapy of arteriovenous malformations. J Neurosurg 66:748-754. CrossRef Medline

Weber TG, Osl F, Renner A, Poschinger T, Galban S, Rehemtulla A, Scheuer W (2014) Apoptosis imaging for monitoring DR5 antibody accumulation and pharmacodynamics in brain tumors noninvasively. Cancer Res 74: 1913-1923. CrossRef Medline

Weissberg I, Veksler R, Kamintsky L, Saar-Ashkenazy R, Milikovsky DZ, Shelef I, Friedman A (2014) Imaging blood-brain barrier dysfunction in American football players. JAMA Neurol 71:1453-1455. CrossRef Medline

Weissberg I, Wood L, Kamintsky L, Vazquez O, Milikovsky DZ, Alexander A, Oppenheim H, Ardizzone C, Becker A, Frigerio F, Vezzani A, Buckwalter MS, Huguenard J, Friedman A, Kaufer D (2015) Albumin induces excitatory synaptogenesis through astrocytic TGF- $\beta$ /ALK5 signaling in a model of acquired epilepsy following blood-brain barrier dysfunction. Neurobiol Dis 78:115-125. CrossRef Medline

Wolman M, Klatzo I, Chui E, Wilmes F, Nishimoto K, Fujiwara K, Spatz M (1981) Evaluation of the dye-protein tracers in pathophysiology of the blood-brain barrier. Acta Neuropathol 54:55-61. CrossRef Medline

Yang L, Froio RM, Sciuto TE, Dvorak AM, Alon R, Luscinskas FW (2005) ICAM-1 regulates neutrophil adhesion and transcellular migration of TNF-alpha-activated vascular endothelium under flow. Blood 106: 584-592. CrossRef Medline

Yoon KW, Covey DF, Rothman SM (1993) Multiple mechanisms of picrotoxin block of GABA-induced currents in rat hippocampal neurons. J Physiol 464:423-439. CrossRef Medline

Yoshiyama M, Roppolo JR, de Groat WC (1995) Effects of GYKI 52466 and CNQX, AMPA/kainate receptor antagonists, on the micturition reflex in the rat. Brain Res 691:185-194. CrossRef Medline

Zangen A, Hyodo K (2002) Transcranial magnetic stimulation induces increases in extracellular levels of dopamine and glutamate in the nucleus accumbens. Neuroreport 13:2401-2405. CrossRef Medline

Zangen A, Roth Y, Voller B, Hallett M (2005) Transcranial magnetic stimulation of deep brain regions: evidence for efficacy of the $\mathrm{H}$-coil. Clin Neurophysiol 116:775-779. CrossRef Medline

Zlokovic BV (2008) The blood-brain barrier in health and chronic neurodegenerative disorders. Neuron 57:178-201. CrossRef Medline 